\title{
تصور مقترح لتفعيل التعلم عن بعد لدى المعاقين سمعيًا في ضوء مجتمع المعرفة
}

د.نعيمة محمد محمد سيد عبدالله

استاذ مساعد بجامعة الامام محمد بن سعود 
هدفت الدراسة إلى التعرف على التعلم عن بعد من حيث المفهوم وعناصره وأبعاده

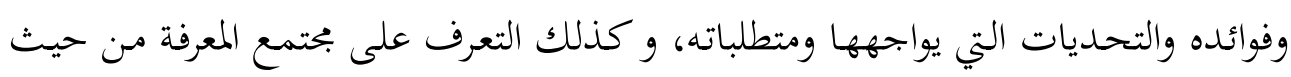

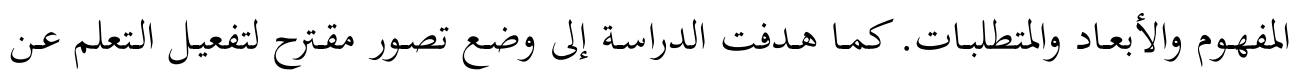

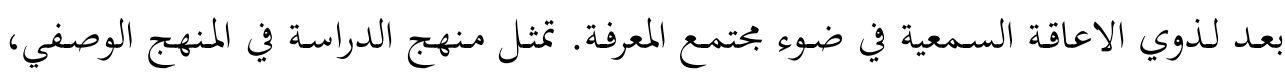

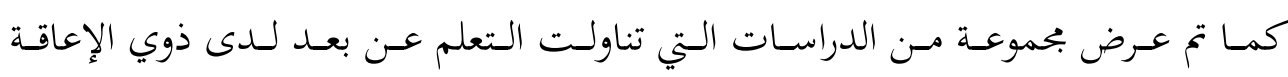

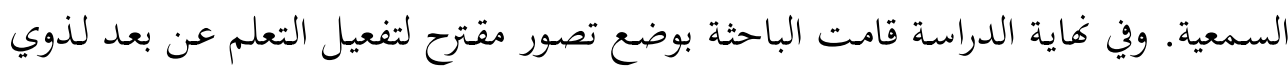

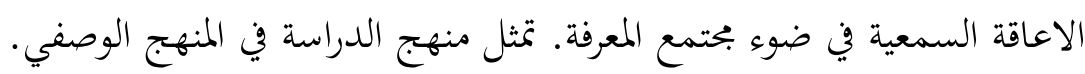

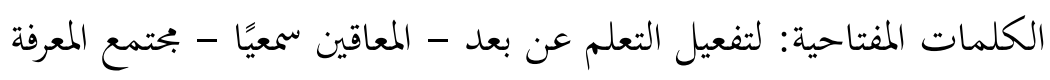

Summary 
Proposal Framework To Activate Distance Learning For The

Hearing Impaired In Light Of Knowledge Society

The study aimed at identifying the concept of distance learning In terms of concept, its components, dimensions, benefits, challenges and requirements, as well as the knowledge society in terms of concept, dimensions and requirements. Also, the study aimed at preparing a proposed proposal framework to activate distance learning for the hearing impaired in light of knowledge society. The study methodology was presented in the descriptive approach, and a series of studies which interested in distance learning for the hearing impaired were presented. At the end of the study, the researcher preparing a proposed proposal framework to activate distance learning for the hearing impaired in light of knowledge society.

Key Words: Activate Distance Learning - Hearing Impaired - Knowledge Societ 
يقاس تقـدم الأمم وتطورهـا بما تمتلكهه مـن مـوارد بشرية وليس بمـا تمتلكه مـن ثروات

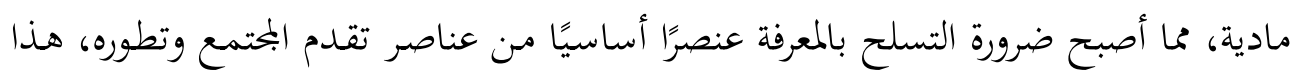

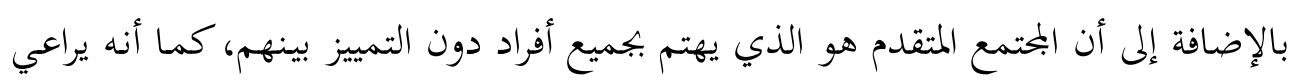

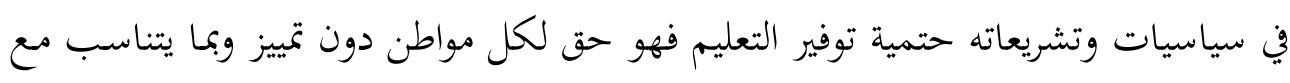
قدراته الخاصة.

هذا ويعد التعلم عن بعد من أبرز مـا نتج عن دمج تكنولوجيا التعليم التعلمي في

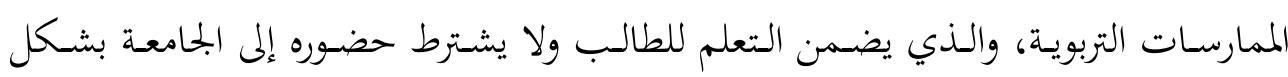

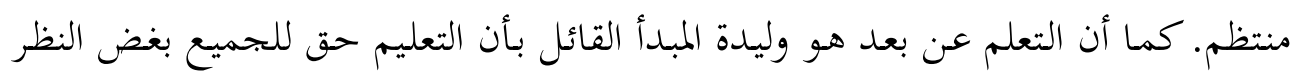

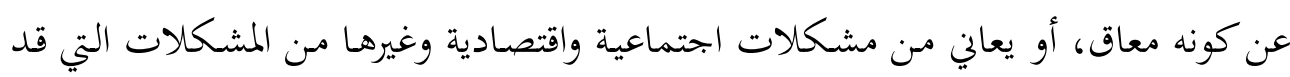

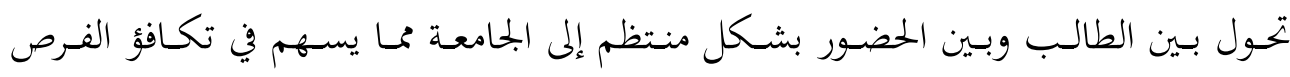
التعليمية بين جميع أفراد المجتمع من أجل الحصول الحفور بنحل على المعرفة المتنوعة والمتعددة.

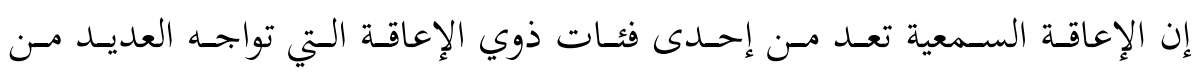

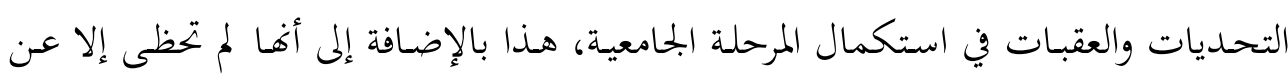

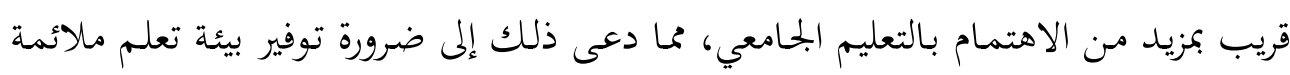

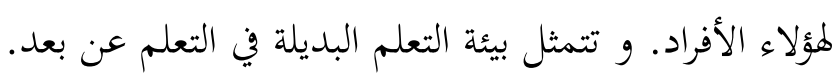

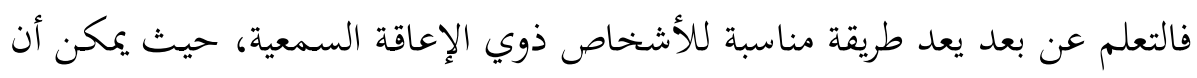

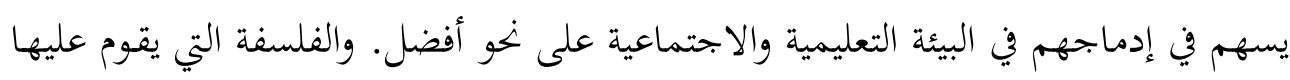

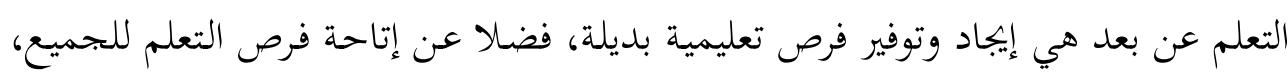

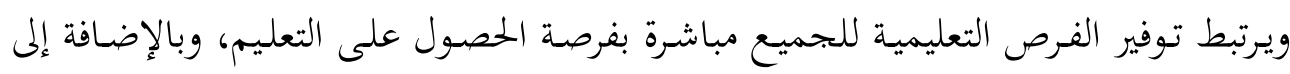

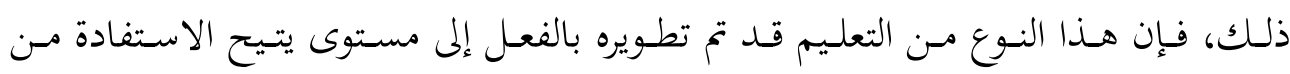
تكنولوجيات المعلومات والاتصالات من التطبيقات المبتكرة فضلا عن فرص التعلم البديلة.

.(Liakou\&Manousou,2015,72 ; Oswal \& Meloncon, 2014, 276) بالإضافة إلى ذلك، فهو يعد أيضًا بمثابة عملية التعليم الرميمي التي توفر التعليم عندما

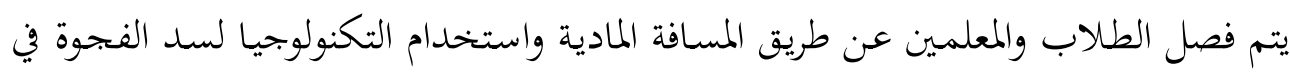

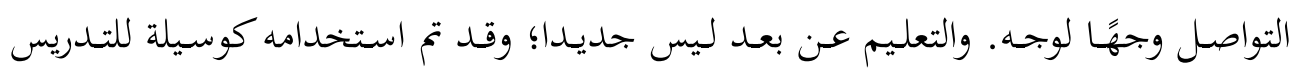


والتعلم لعدد لا يحصى من الأفراد لأكثر من 100 سنة. ويمكن أن تكون التعليمات متزامنة

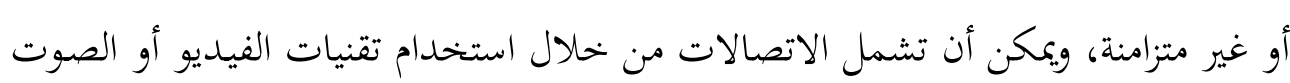

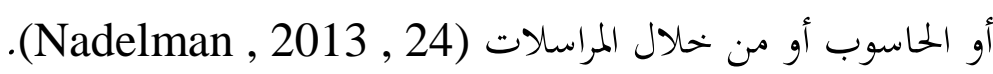

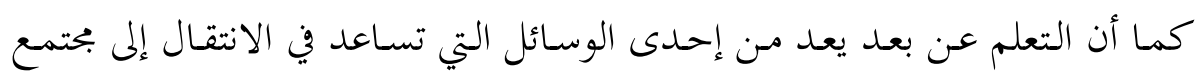

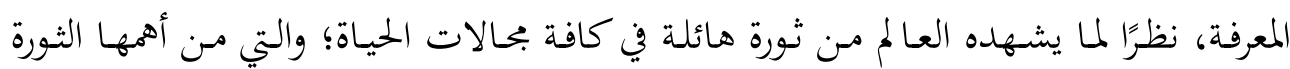

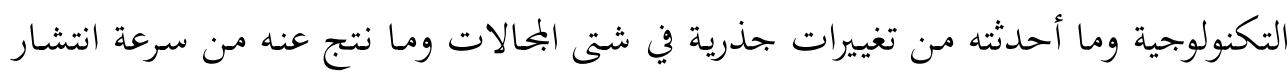

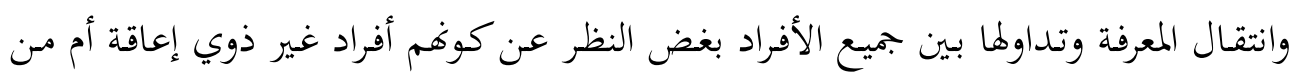
ذوي الإعاقة، وبالتالي ساهم ذلك في أن أصبح العالم قرية صغيرة.

\section{مشكلة البحث}

يعد التعليم الجامعي المرحلة النهائية لمرحلة التعليم والتي يمكن مـن خحلال استكمال

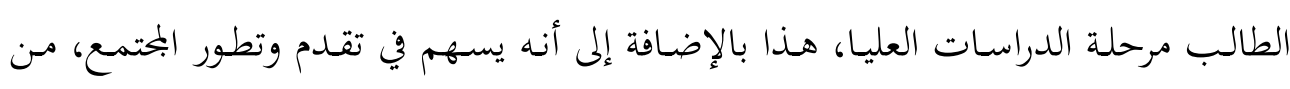

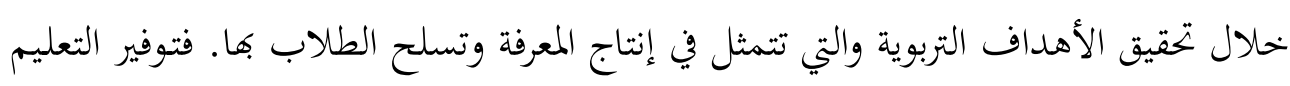

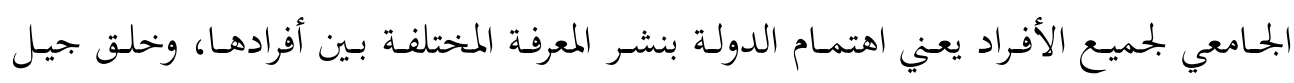

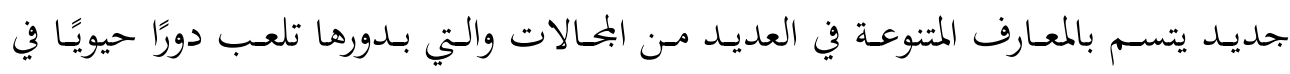
الانتقال إلى بحتمع المعرفة.

إن بحتمع المعرفة هو نتيجة لما أحدثثه ثورة الاتصالات وما يشهده الواقع الحالي من

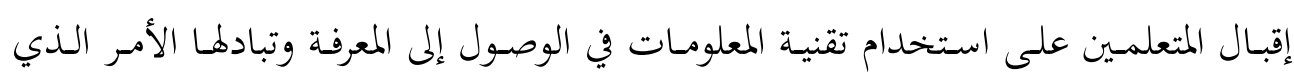

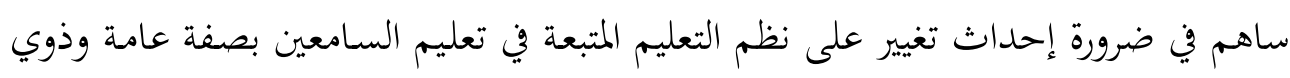

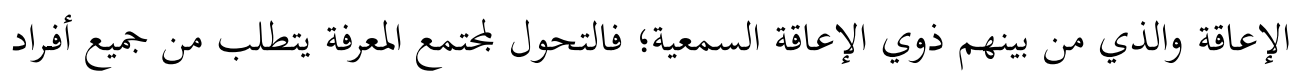

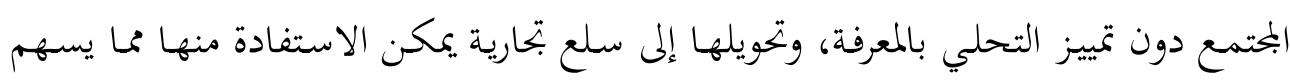

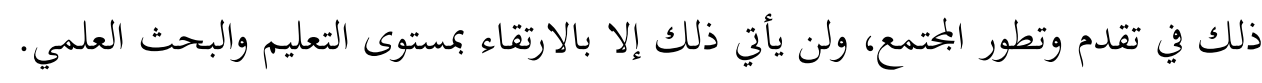

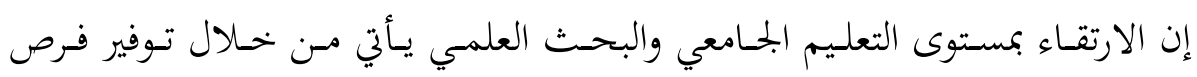

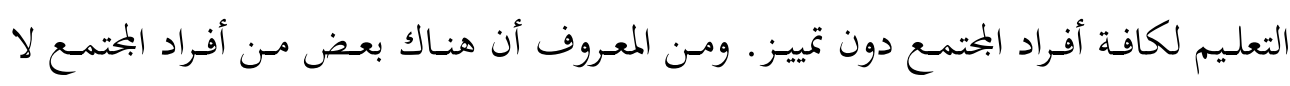


يمكنهم استكمال مراحلهم التعليمية وذلك نتيجة لوجود إعاقة تحول بينهم وبين استكمال

مراحل تعليمهم.

و من بين الإعاقات التي تواجه العديد من التحديات والعقبات في استكمال التعليم

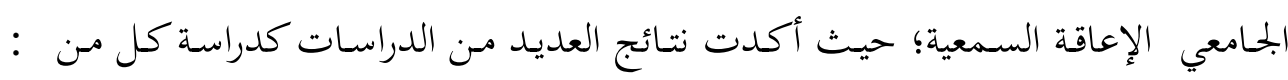

Mpofu \& Chimhenga , 2013; Kigotho,2016; Charles,2015;

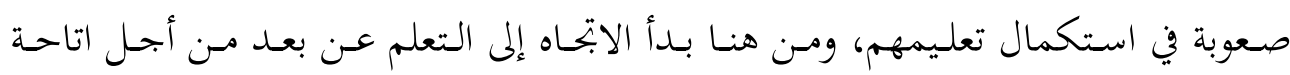

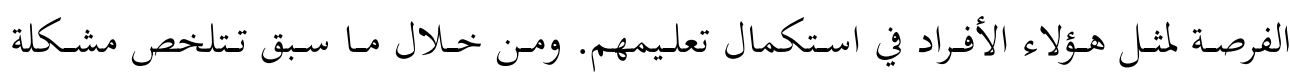

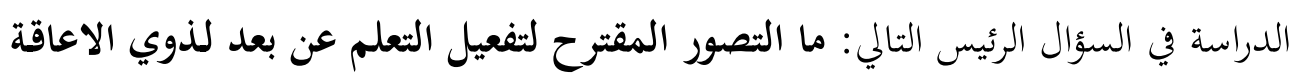

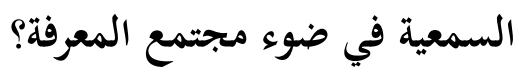

$$
\text { أهداف البحث }
$$

تحدف الدراسة الحالية إلى وضع تصور مقترح لتفعيل التعلم عن بعد لذوي الاعاقة السمعية في ضوء بحتمع المعرفة.

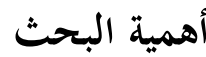

تنقسم أهمية الدراسة الحالية إلى ما يلي: الإلي الهمئ

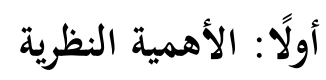

تشتق الأهمية النظرية للدراسة الحالية مـ أهمية الموضوع الذي تنتاوله، بالإضافة إلى الى

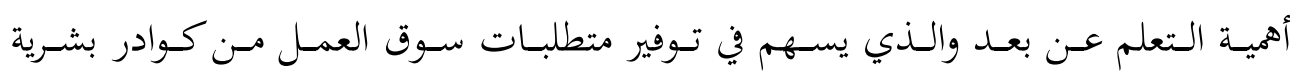
متخصصة التي تسهم في الانتقال إلى بحتمع المعرفة، هذا بالإضافة إلى أن الدراسة الحالية تأتئي

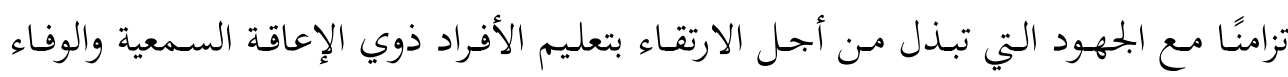
بمتطلبات بحتمع المعرفة.

ثانيًا: الأهمية التطبيقية

تنبثق الأهمية التطبيقية للدراسة الحالية في أها تعد من الدراسات المستقبلية التي هتم

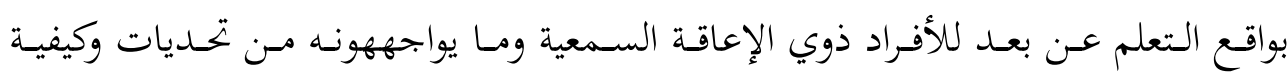


التصدي لتلك التحديات من أجل مواكبة متطلبات بحتمع المعرفة، كما أن الدراسة الحالية

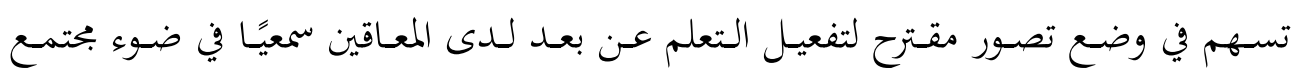
المعرفة.

\section{مفاهيم البحث}

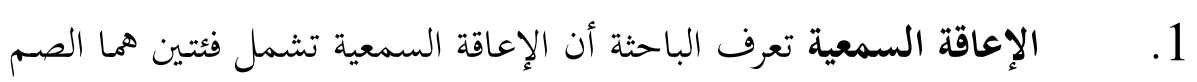

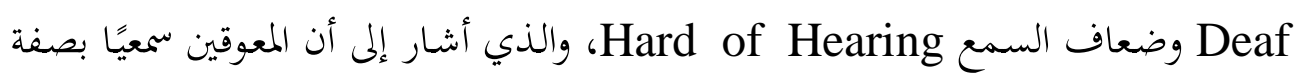

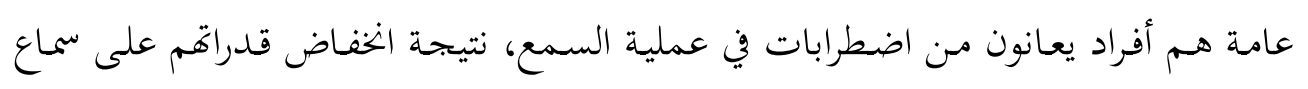

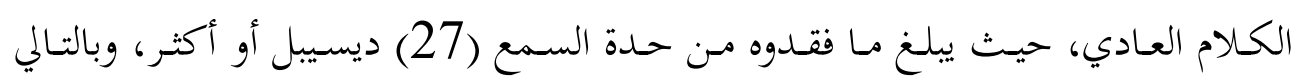

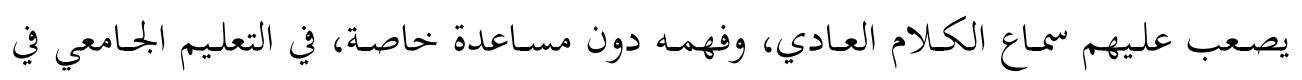
ضوء بجتمع المعرفة (سيد، 2014، 18) التعلم عـن بعـد: وتعرفه الباحثة على أنه الوضع الذي يتيح للأفراد ذوي الإعاقة السمعية لاستكمال تعليمهم الجامعي من خلال استخدام تكنولوجيا الاتصالات الحلديثة.

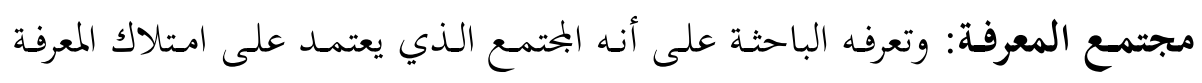
كأهم موارد التنمية الاقتصادية والاجتماعية بدلًا من الموارد المالية.

$$
\text { محددات البحث }
$$

الحدود الموضوعية: تصور مقترح لتفعيل التعلم عن بعد لذوي الاعاقة السمعية في

$$
\text { ضوء بجتمع المعرفة. }
$$

الحدود المكانية: تنحصر في دراسة التعلم عن بعد بالمملكة العربية السعودية

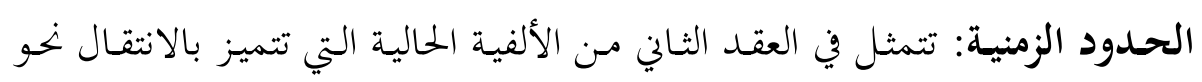

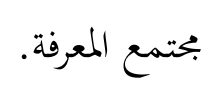

الإطار النظري والدراسات السابقة أولاً الإطار النظري 


\section{المحور الأول: التعلم عن بعد}

يعد التعلم عن بعد أحد الاتجاهـات الحديثة التي اهتمد بعد بتوفير التعليم للأفراد غير

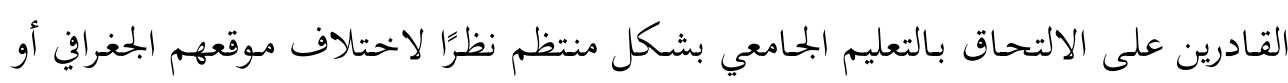

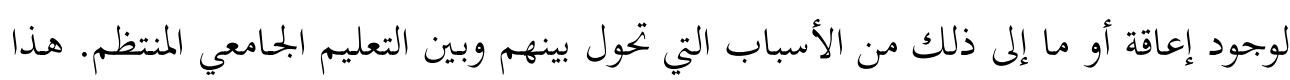

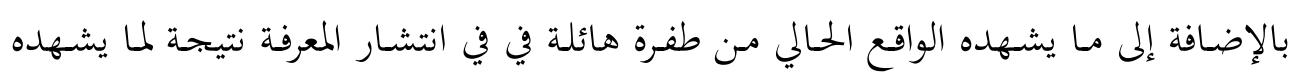
الواقع من ثورة تكنولوجية الأمر الذي يتطلب ضرورة التسلح بالمعرفة.

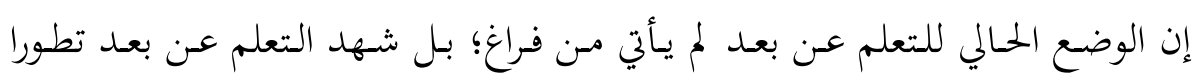

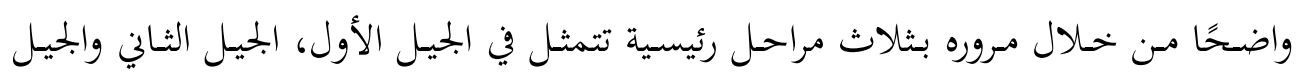

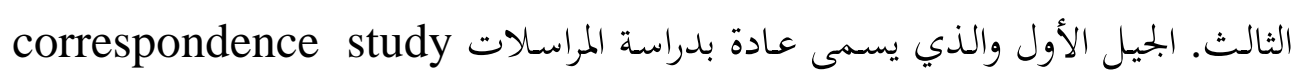

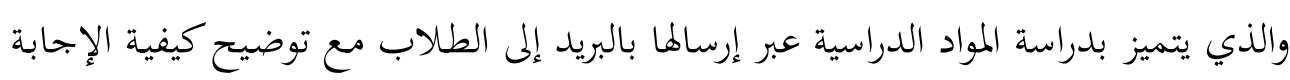

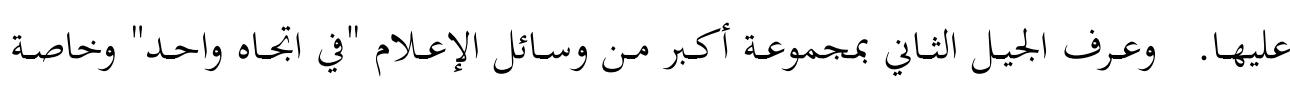

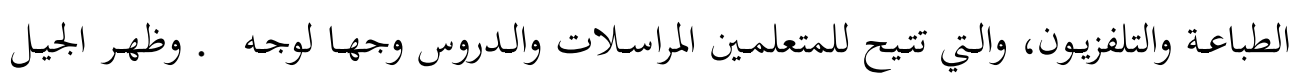

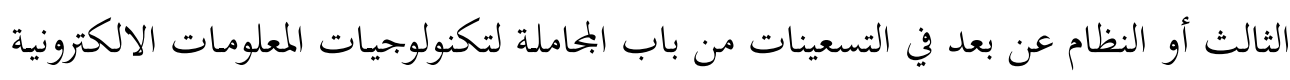

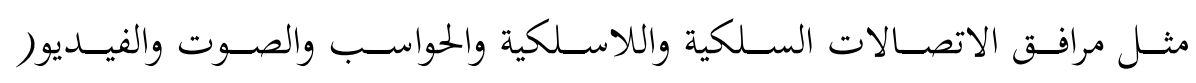

.Dodo,2013,30

وعرف التعلم عن بعد على أنه التعليمات التي يتم فصل المعلم والطالب عن بعد

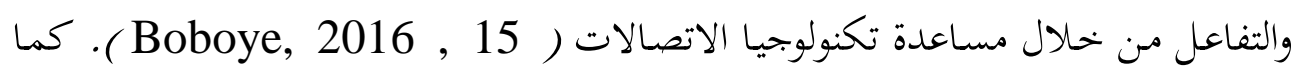
عرف على أنه الوضع الذي يُفصل فيه المتعلمون عن بعد عن معلميهم، وينطوي على توفير الاتصات (

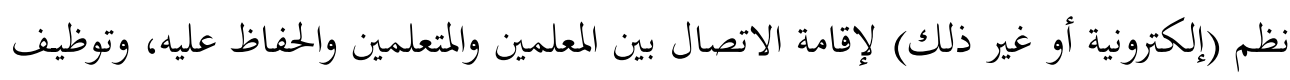

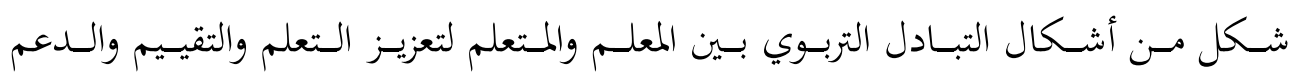

.(Panchabakesan,2011,113)

كمـا عرف أيضًا على أنه استخدام وسائل الإعلام المطبوعة أو الإلكترونية لتقديم

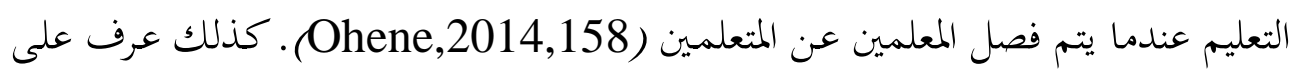

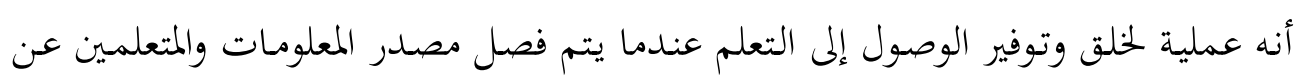

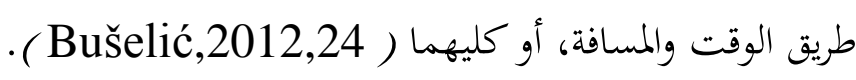


ومن خلال العرض السابق للتعريفات التي تناول التعلم عن بعد؛ ترى الباحثة أن جميع

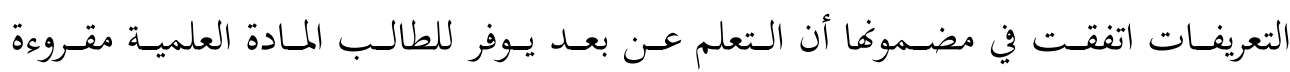

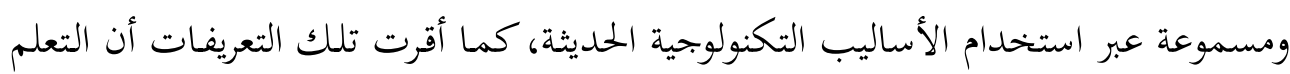

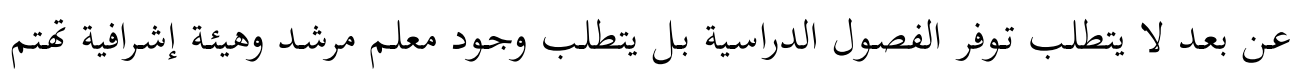
بالإشراف على سير العملية التعليمية بين المتعلم والمعلم.

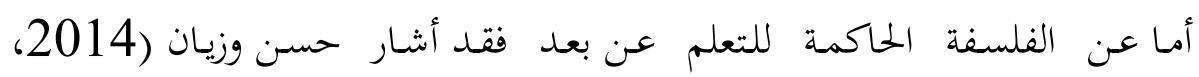
ص282) إلى أها أخذت في حسباها آثار الثورة المعرفية والثورة التكنولوجية وكذلك بعلك آثار

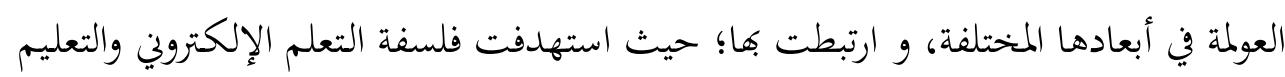
عن بعد ما يأتي: تكوين المواطن العصري تكوينًا شاملا يسهم في إتقانه التخصص الذي يختاره ومن ثم يسهم في تنمية بحتمعه. تنمية الابحاهات الإيجابية لدى المتعلم نحو استقراء المعرفة من شتى مصادرها على نحو ناقد وبناء. إكساب المتعلم مهارات التعلم الذاتي واكتساب المعارف بصورة تساعده على تنمية ذاته وتطويرها، ومن ثم إمكانية الحصول على فرص أعلى للترقي.

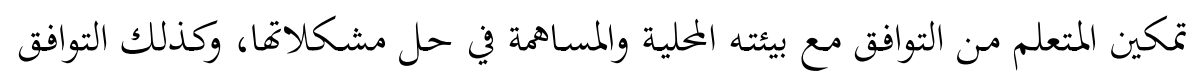
مع البيئة العالمية والمحافظة عليها. إكساب المتعلم مهارات ومقومات التعامل مع الأجهزة العلمية والتكنولوجية.

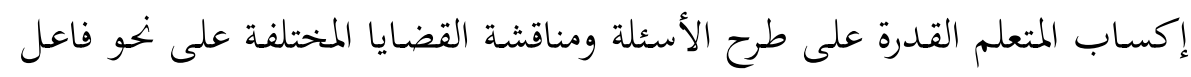
ومرن. الاسهام في توفير مادة تعليمية متميزة على الشبكة العنكبوتية، وتمكين المتعلم من التعامل مع تغير المعلومات والمعارف وتعقدها. تأكيد التوجه نهو الاستقلالية في التعلم وعلى النقد الموضوعي.

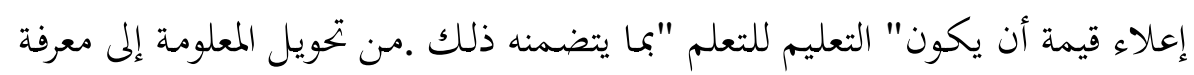
جديدةُ تترجم إلى تطبيقات عملية مهمة ومفيدة . 
(10) إتاحة فرص الحراك المهني أمام أبناء البجتمع، لتبوؤ مهن جديدة في ضوء متطلبات الأجهزة العلمية والتكنولوجية المطورة.

(11) إتاحة الفرص للمتفوقين من الطلبة لإظهار تفوقهم وسرعة الانتهاء من الدراسة في

$$
\text { وقت أقل من زملائهم السامعين. }
$$

(12) تقليل الضغط على الجامعات الحكومية بأماكنها المحدودة، وإتاحة الفرص التعليمية أمام

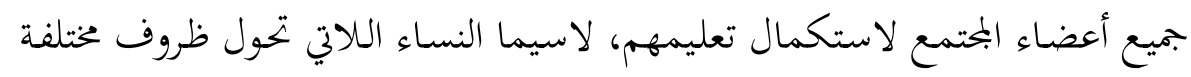

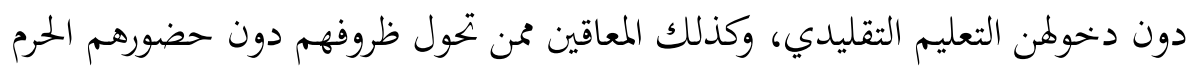
الجامعي وانتظامهم في الدراسة.

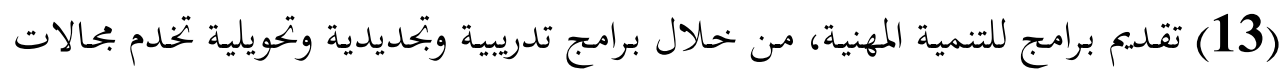
التنمية في المختمع.

$$
\text { أنماط التعلم عن بعد }
$$

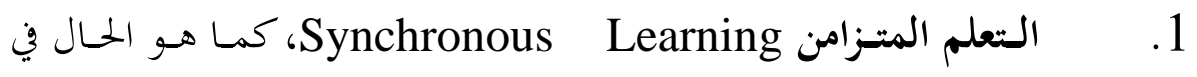

التـدريس التقليدي، المعلم والطلاب موجـودين في نفس الوقت، وإن لم يكن بالضـرورة في

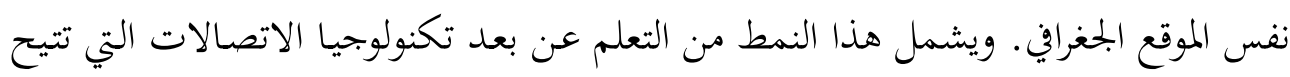

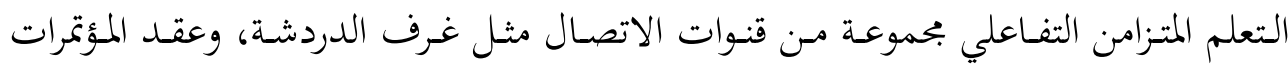

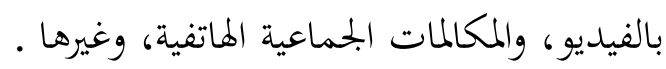

2. أن يتواجد المعلم والمتعلم في مكان أو وقت واحد، ويحدث هذا النوع من خحلال التكنولوجيا

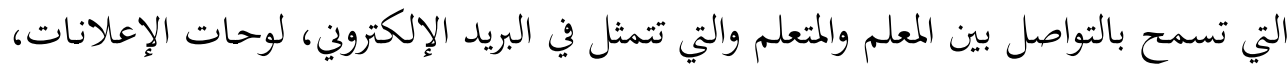
والمنتديات، وبحموعات النقاش المختلفة \& Coogle \& .Floyd , 2015 , 175 ; Ahmad \& Bokhari, 2013 , 546) 
تتمثل عناصر التعلم عن بعد فيما يلي:

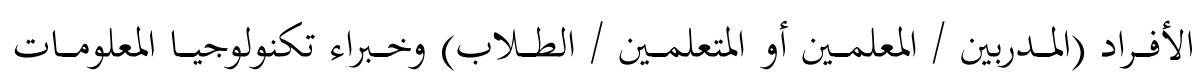

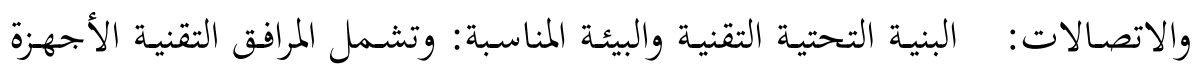

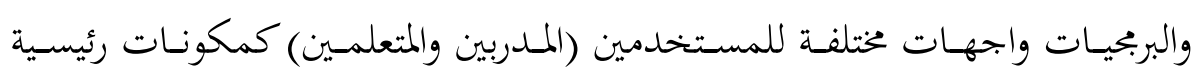

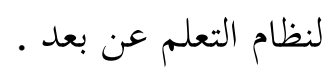

أدوات الاتصـال والمعرفـة: فــأدوات الاتصـال مثـل الإنترنست وشـبكة مـن المتعلمـين

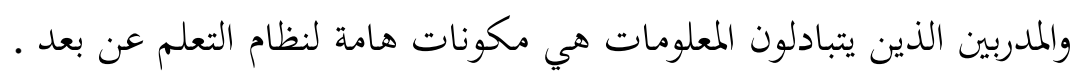

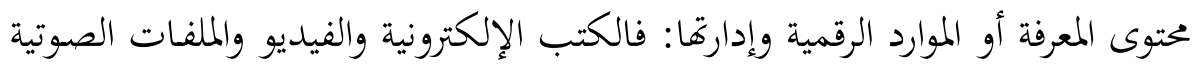

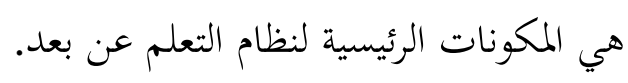

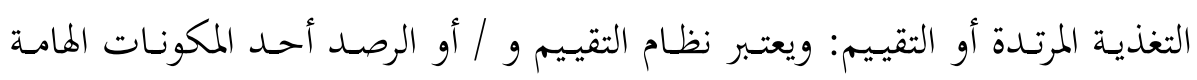

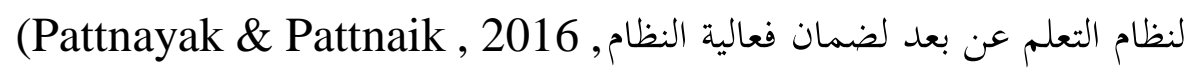

فوائد التعلم عن بعد

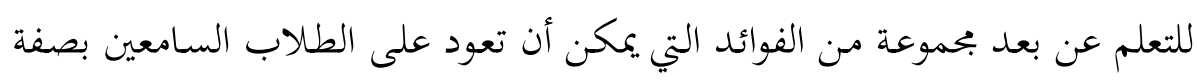

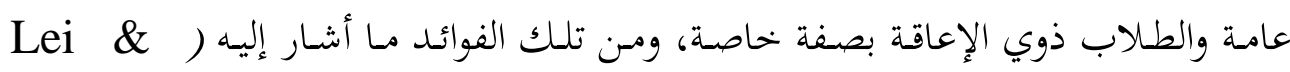
Gupta,2010,623-624; Pittman , 2013 , 16; Bušelić,2012,26 ; والتي يمكن توضيحها على النحو Topaloglu \& Topaloglu , 2009 , 1009 التالي:

تزويد الطلاب بالفرص لاستخدام بنيات تحفيزية في إطار النظرية المعرفية الاجتماعية

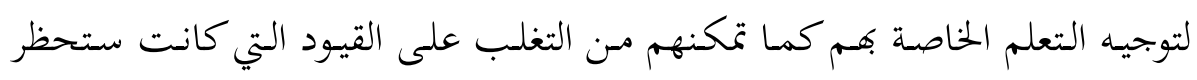

$$
\text { مشاركتهم في التعلم. }
$$

(2) يوفر التعلم عن بعد الوصول غير المحدود للطلاب إلى المعلومات في أي وقت.

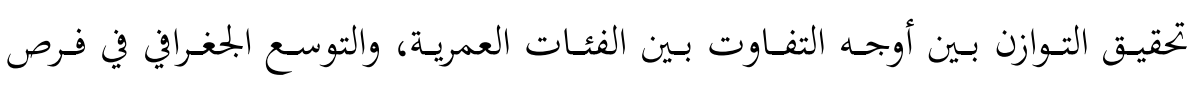

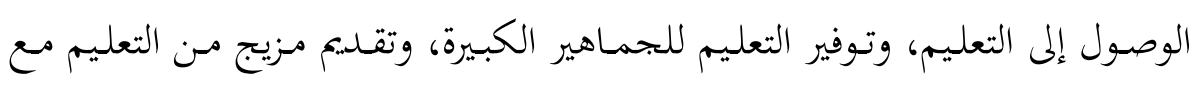

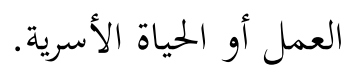




$$
\text { مساعدة الأفراد في الحصول على المعرفة مع توفير الوقت والمال. }
$$

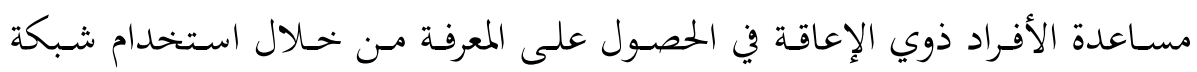

الإنترنت.

ولضمان الاستفادة من التعلم عن بعد؛ هناك بحموعة من العوامل التي تسهم في تعزيز

$$
\text { التعلم عن بعد والتطور السريع له، وتتمثل لك العوامل في الآتي: }
$$

الحاجة إلى ضمان التعليم مدى الحياة.

(2) زيادة فرص الحصول على التعليم والتدريب المهني باستمرار.

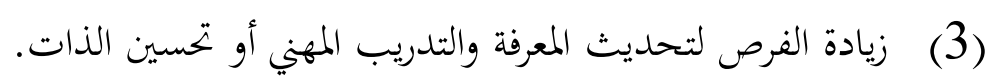

(4) ز زيادة ربحية الموارد التعليمية؛ وتحسين نوعية الحخدمات التعليمية القائمة.

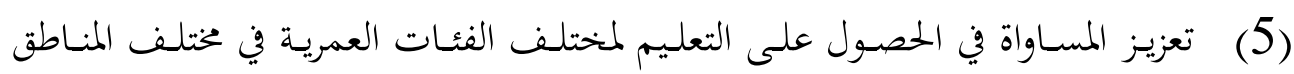

$$
\text { الجغرافية. }
$$

توفير دورات تدريبية قصيرة الأجل وفعالة لفئات معينة من الطلاب.

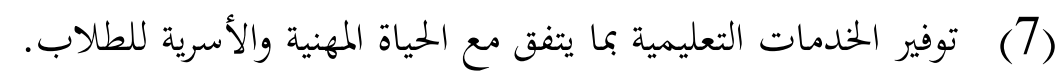

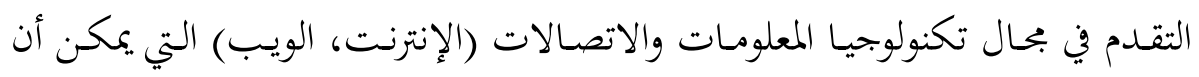

$$
\text { تزيد من عدد المواد التي تدرس على بعد. }
$$

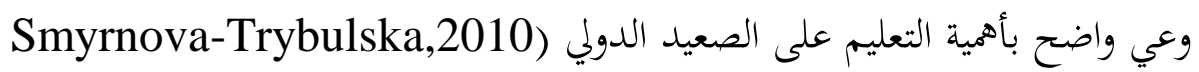

$$
\text { (, 139-140 }
$$

\section{تحديات التعلم عن بعد}

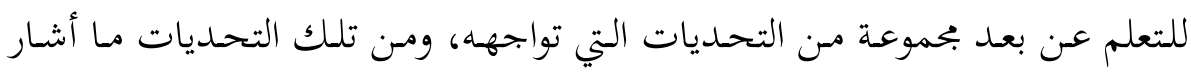

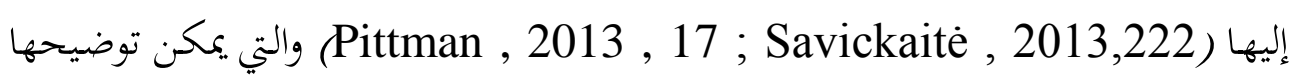
على النحو التالي:

نقص التغذية الراجعة A lack of feedback فالتعلم عن بعد ليس مثل الفصول الدراسية العادية، ففي التعلم عن بعد لا يحصل المتعلم على ردود فعل المعلم على الفور؛ بل ينتظر مراجعة المعلم للمهمة وإرساله التعليق عليها. 
Difficult technology and صعوبة النكنولوجيا وإمكانيـة الوصسول accessibility

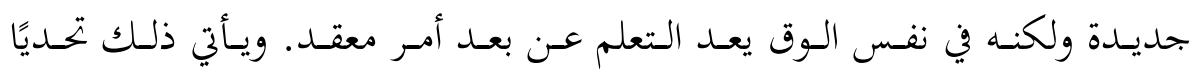

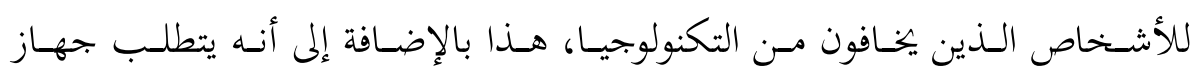
كمبيوتر متصل بشكل مستمر بالإنترنت.

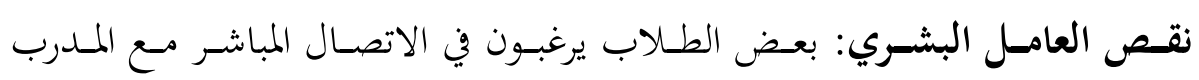
والطلاب الآخرين. انعـام السيطرة: يتطلب التعلم عن بعد ضبط النفس وإرادة المتعلم لأنه يجب أن يدرس بشكل مستقل.

\section{متطلبات التعلم عن بعد للأفراد ذوي الإعاقة السمعية}

أشارت دراسة Debevc et al.,(2012, 5 إلى أن متطلبات تطبيق التعلم عن بعد للأفراد ذوي الإعاقة السمعية تتمثل في الآتي:

$$
\text { توفير جميع المعلومات السمعية بصريا. }
$$

(2) ضمان توافر ترجمات النص المنطوق والمكتوب إلى لغة الإشارة باستخدام الفيديو.

$$
\text { تقديم تقديم العروض النصية والرسوم البيانية. }
$$

أن تكون بنية التعلم الإلكتروني على شبكة الإنترنت بطريقة مفهومة ومنطقية.

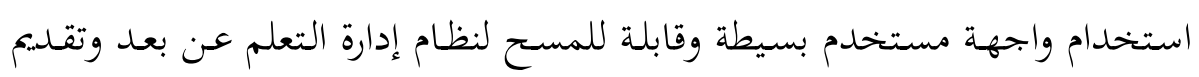

أدوات لتفاعل واجهة المستخدم.

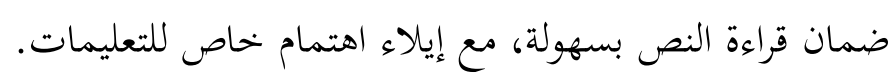

\section{المحور الثاني: مجتمع المعرفة}

يعد مصطلح المعرفة من المصطلحات وليد الثورة التكنولوجية الحالية، فلقد تم استخدم

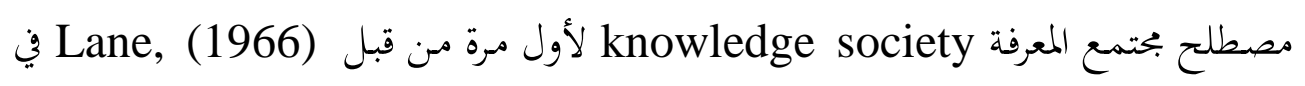


كobin كتاباته، تم بدأ استخدام هذا المصطلح في التوسع من خلال دراسات الباحثين (Valimaa \& Hoffman , 2008; 267) Mansell \& Stehr, 1990

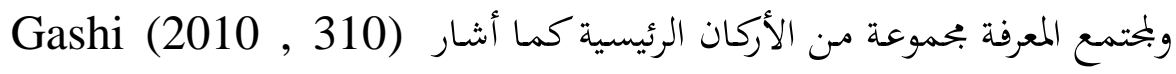
والتي تتمثل في: التعليم، وتكنولوجيا المعلومات والاتصالات؛ فالتعليم هو القطات التطاع الرئيسي

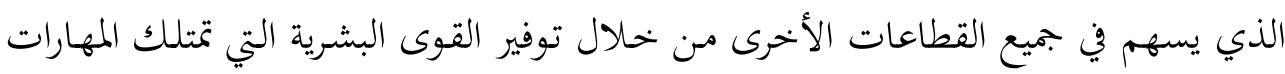

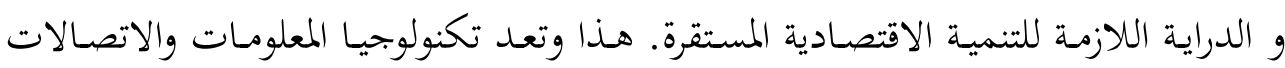
أداة حاسمة لتعليم الطلاب حيث أغا تسهم في تنمية الكوادر البشرية.

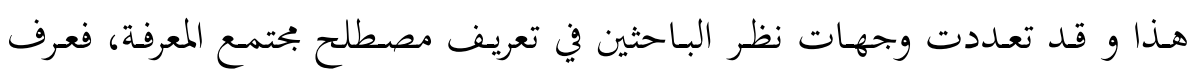

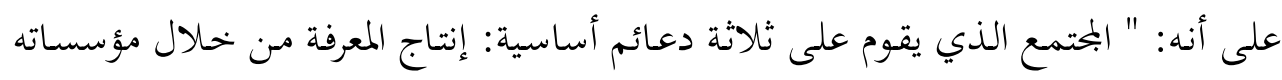

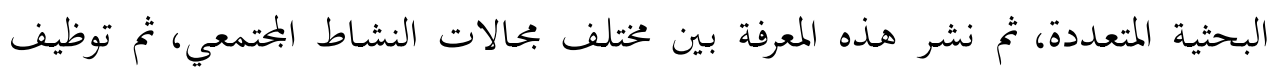

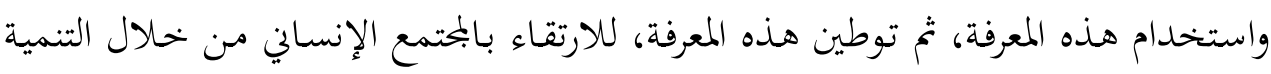

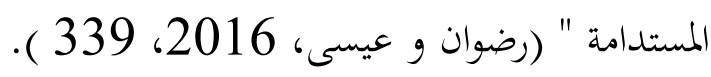

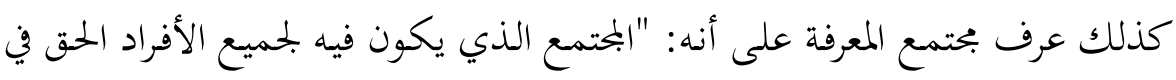

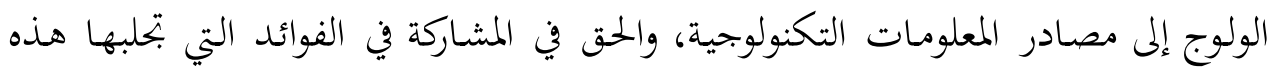

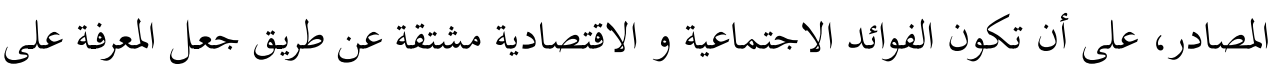

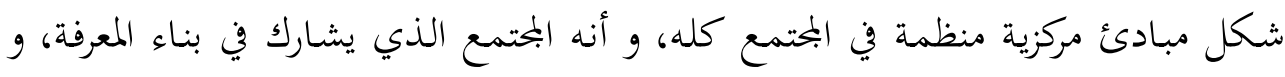

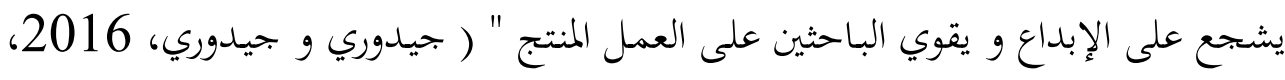
. (148-147

كما عرف بأنه: "بجتمع تشترك شريحة كبيرة منه في إنتاج المعرفة وإعادة إنتاجها ومن

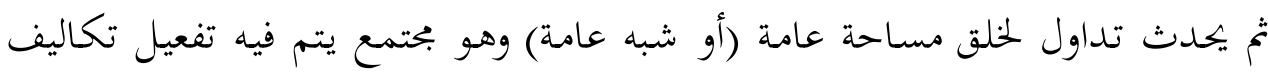

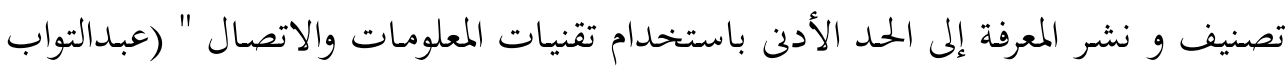
وآخرون، 2017،

كذلك عرف بحتمع المعرفة على أنه " بحموعة من الناس ذوي الاهتمامات المتقاربة،

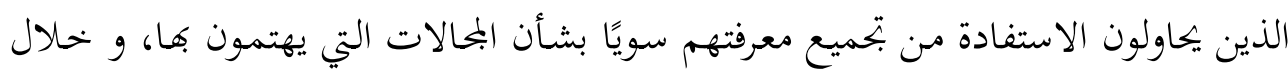

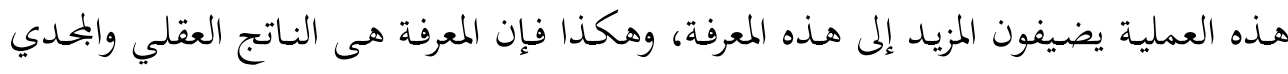


لعمليات الإدراك والتعلم والتفكير " ( القحطاني، 2015، 9). وعرف بحتمع المعرفة على

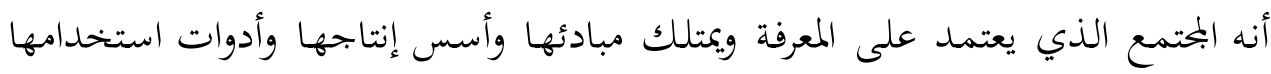
وآليات توظيفها بإبداع كأهم مورد للتنمية الاقتصادية والاجتماعية وكافة أشكال التنمية (زايد، 2012، 28).

يتضح من العرض السابقة للتعريفات التي تناولت بحتمع المعرفة أن هناك اختلاف في وجهات النظر التي تناولت هـا المفهوم، فقـد ركزت بعض التعريفـات على إنتاج المعرفة

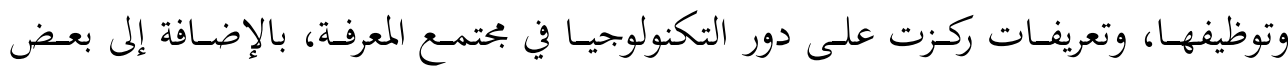

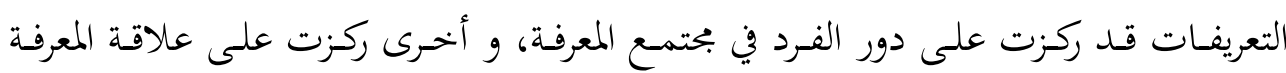
بتحقيق التقدم للمجتمعات.

\section{خصائص مجتمع المعرفة}

يتسم بجتمع المعرفة بمجموعة من الخصائص و التي تتمثل فيما يلي:

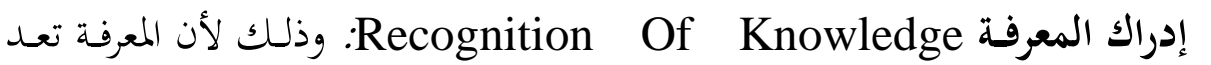

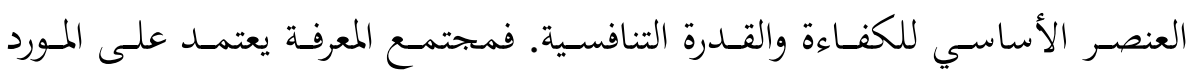

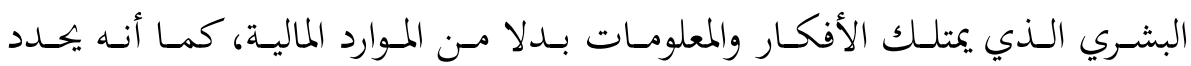
المعلومـات والمعـارف المتعلقـة بالتنميـة البشـرية ويصــرها وييهزهــا ويهولهـا وينشـرها ويستخدمها، فالمعرفة تسهم في توفير العديد من السبل لإضفاء الطابع الإنساني على الى إنى العولمة (Bhuiyan , 2011, 406).

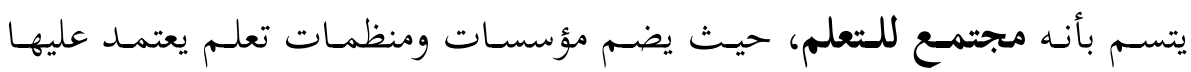

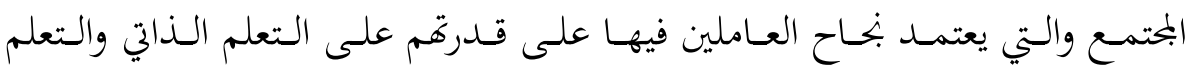

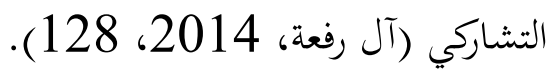
يتسم بحتمع المعرفة بظهور الإدارة الفائقة السرعة التي تعتمد على سرعة الاستجابة التهابة

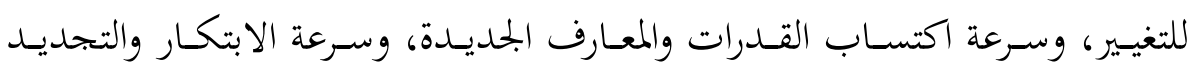

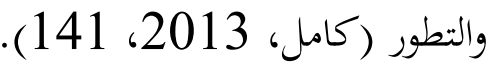


مجتمع المعرفة مجتمع رقمي متطور : حيث يتسم بجتمع المعرفة بالاستخدام

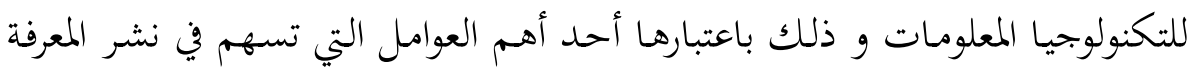

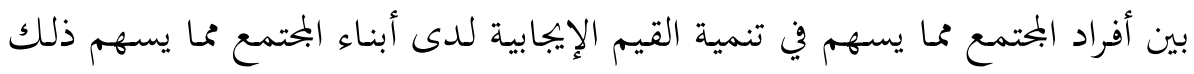

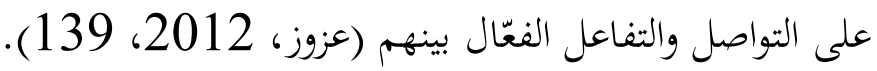

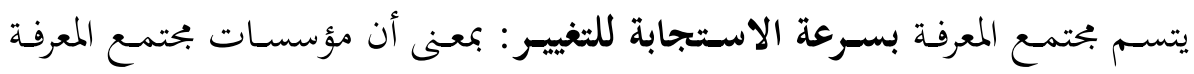

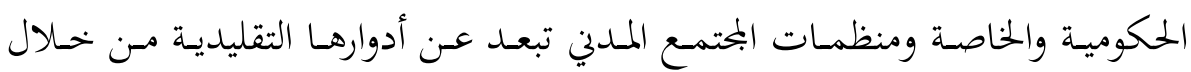

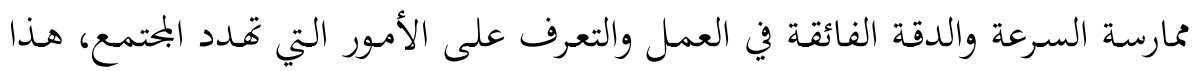

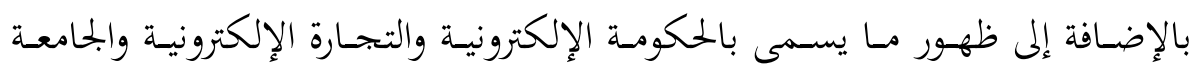

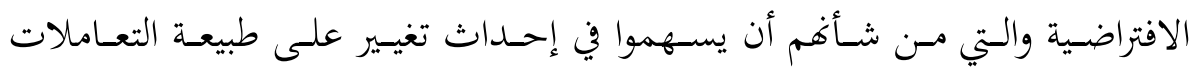
السائدة في المجتمع (القحطاني، 12، 12015 2012). التوجه نحو المنظمة الإلكترونية وهي منظمة تعمل في بحالات مختلفة وتتميز بأهما تنظيم

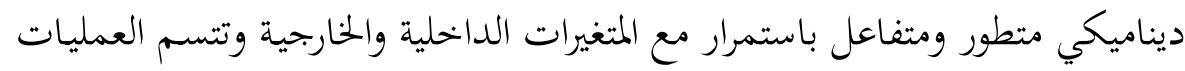

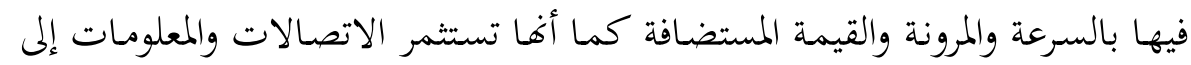

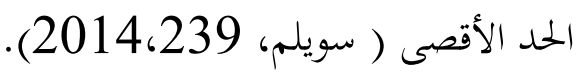

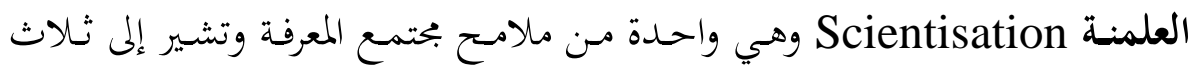

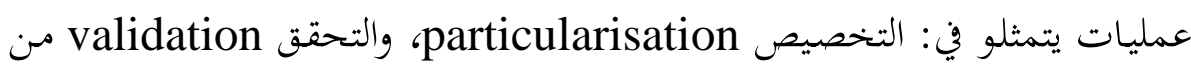
صحة وتعميم generalisation المعرفة الأصلية؛ فالتحديد هو تحديد وفصل المعرفة

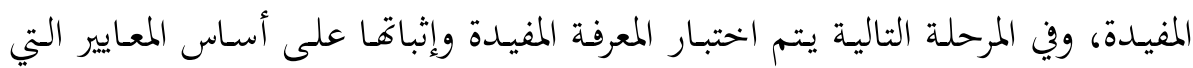

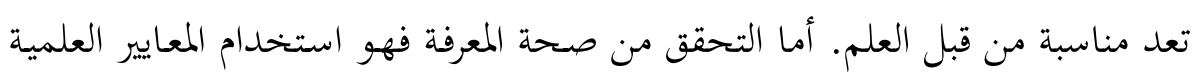

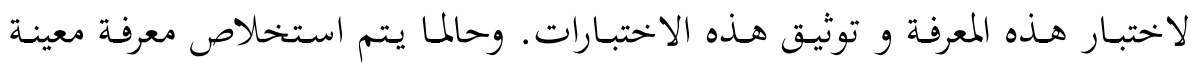

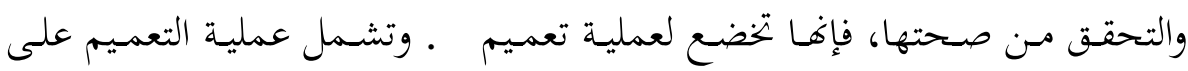

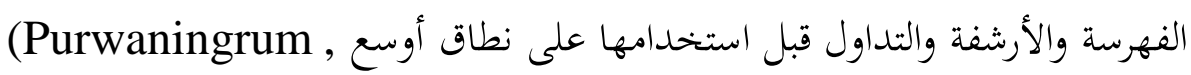
2016, 65) يتضح من العرض السابق لخصائص بجتمع المعرفة أها تؤكد جميعها على أن المعرفة تعد

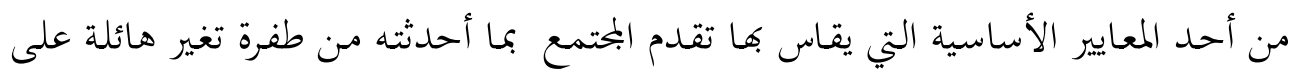


جميع مؤسسات البمتمع و خاصة المؤسسات التربوية و التي يقع على كاهلها إعـاد قوى

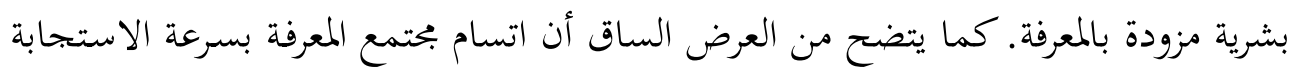

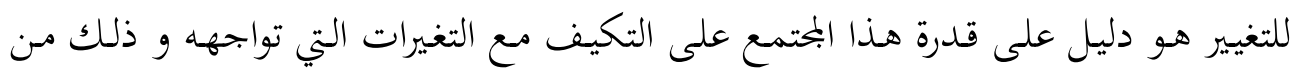
خلال إيباد الحلول العلمية الحديثة للتكيف مع هذا هلئ التغيير.

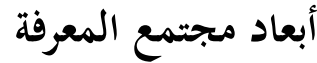

تتمثل أبعاد بحتمع المعرفة في الأبعاد التالية:

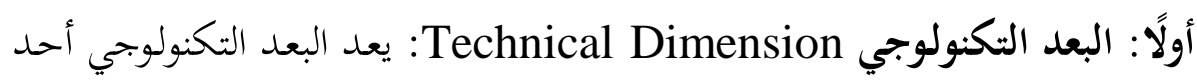

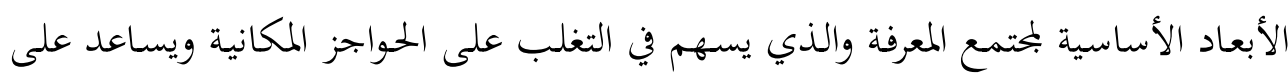
الحصول على المعرفة وسرعة انتشارها. ( Kujath \& Stein , 2009 , 38 ).

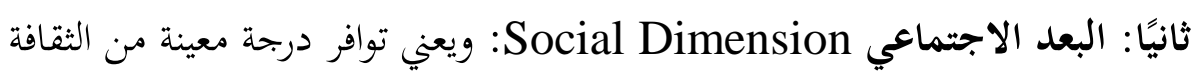

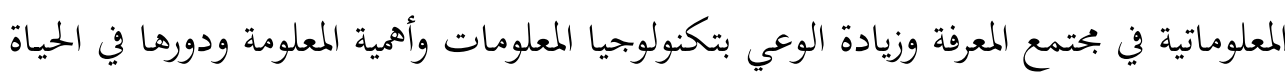

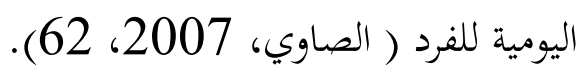

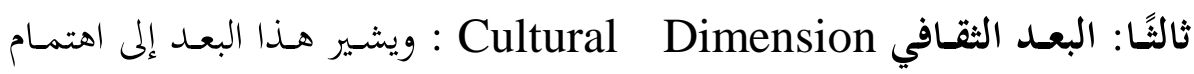

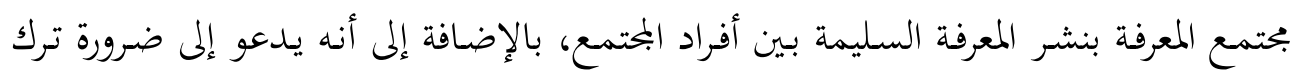

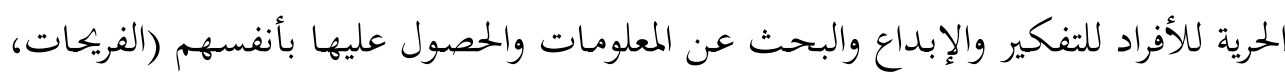
81، 2017

رابعًا: البعـد الاقتصـادي Economic Deminsion : وتتمثل في استغلال

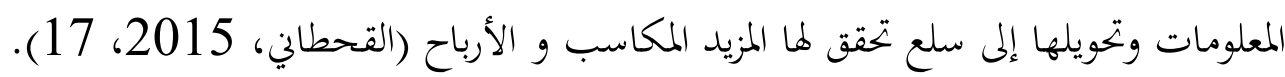

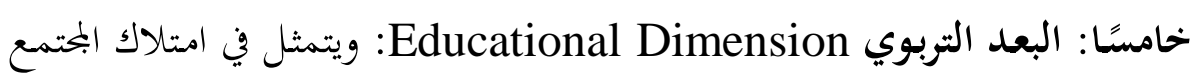

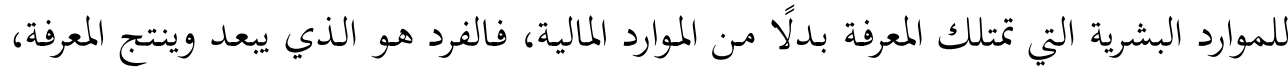

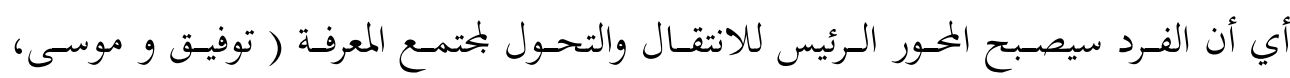
2007 2007 
سادسًا: البعد السياسي Political Dimension: ويشير هذا البعد إلى ضرورة

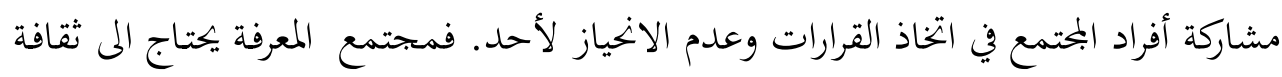

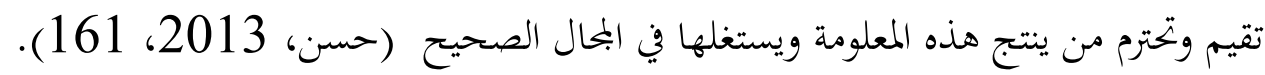

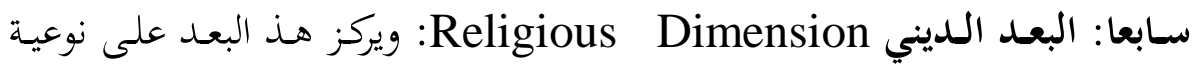

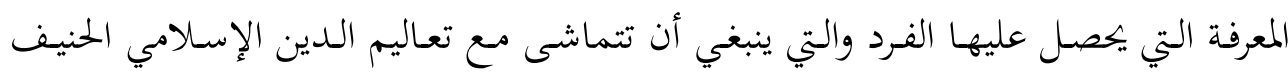

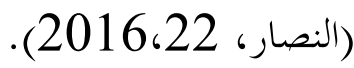

\section{متطلبات مجتمع المعرفة}

أشار بعض الباحثين إلى أن متطلبات بحتمع المعرفة تتمثل فيما يلي:

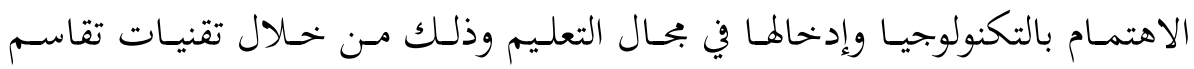
المعلومات والقوائم البريدية الإلكترونية وصفحات الويكي، وعقد المؤتمرات المرئية،

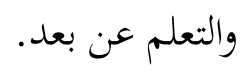

الأخذ بفلسفة التعلم مدى الحياة والذي يهدف إلى استمرار بناء المهارات والخبرات

$$
\text { طوال الحياة الفرد. }
$$

التمكين الإداري للمؤسسات التعليمية وذلك لإتاحة قدر واسع من المرونة للمؤسسة

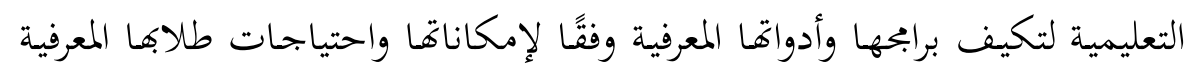
المستمدة من واقعهم الاقتصادي والثقافي والاجتماعي مع التأكيد على مبدأ المساءلة. التحول نهو التعلم للعمل و ذلك بتوظيف المعرفة الملائمة لسوق العمل.

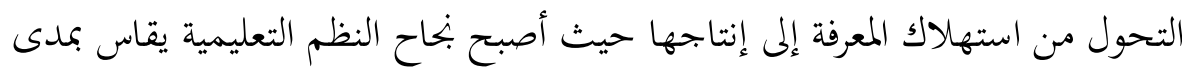

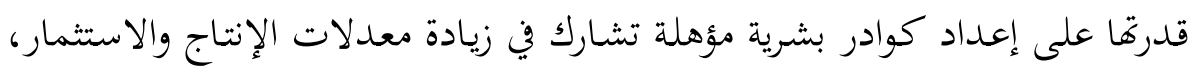

$$
\text { وتسهم بإيجابية في بناء صرح التحضر العلمي. }
$$

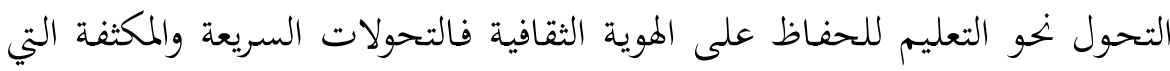

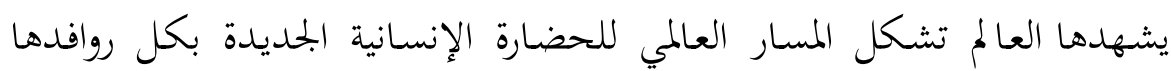

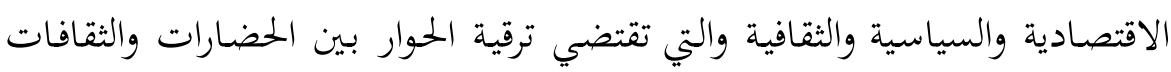

$$
\text { والتعايش مع الآخرين. }
$$


التحول نحو المدرسة البحتمعية حيث أن التحولات والتغيرات التي يتسم بها بحتمع المعرفة

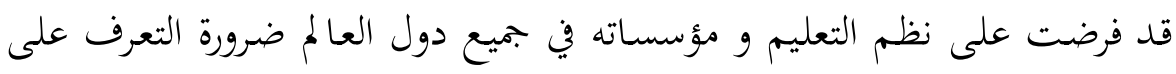

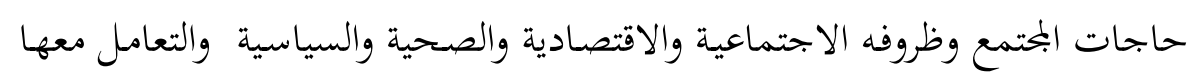

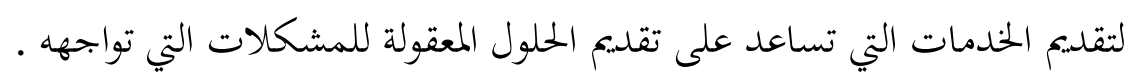

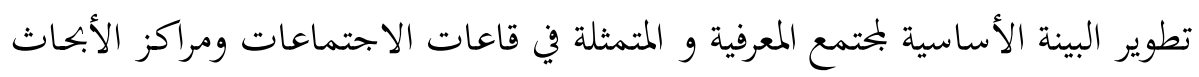

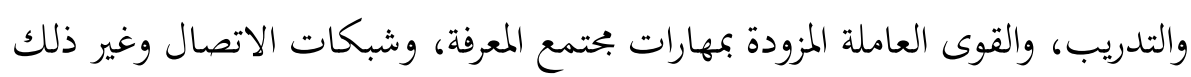

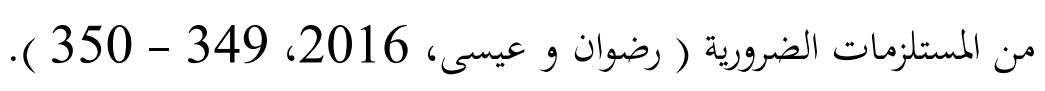

\section{ثانيًا: دراسات وبحوث سابقة}

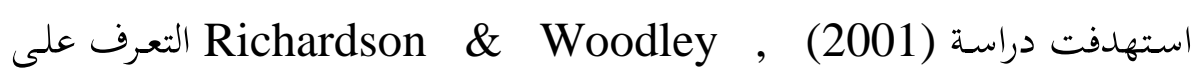
مقاربات وتفضيلات الطلاب الصم الذين يدرسون عن طريق التعلم عن بعد والذين يفضلون

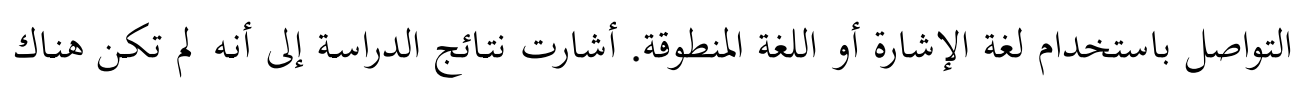

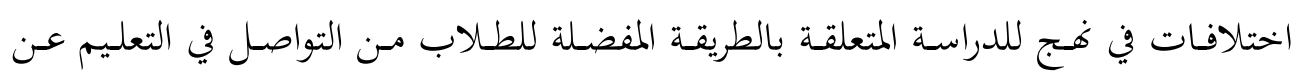

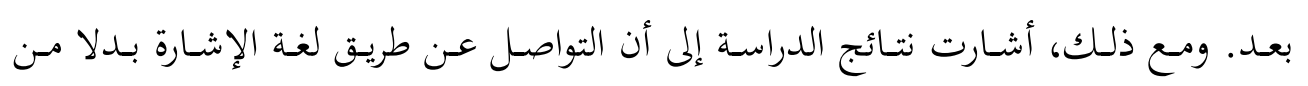
الكلام له عواقب عملية مختلفة حيث تزيد من أعباء الدراسة للطلاب.

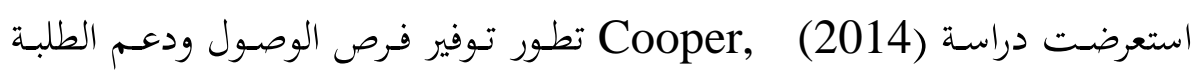

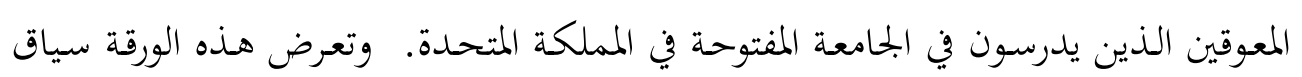

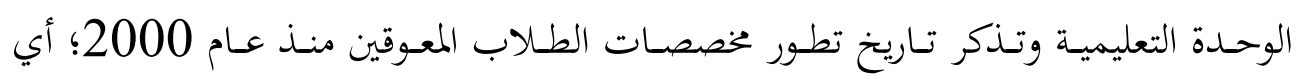

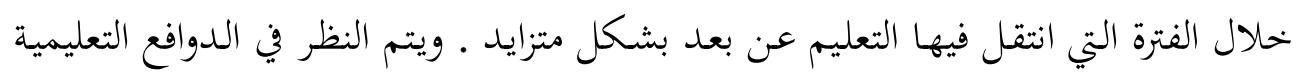

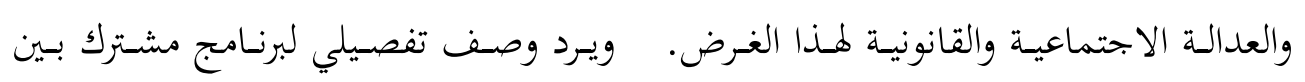

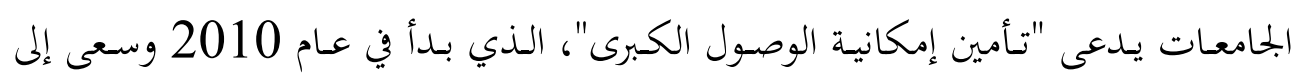

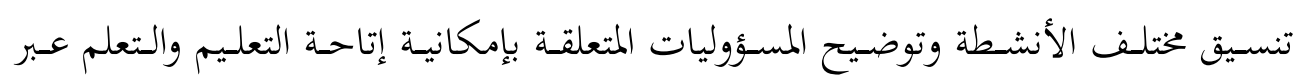
الإنترنت للجميع، بما في ذلك الطلاب ذوي الإعاقة.

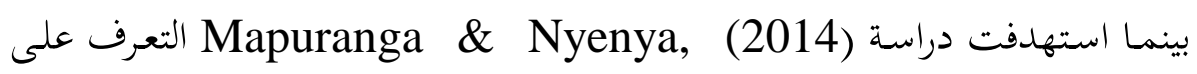

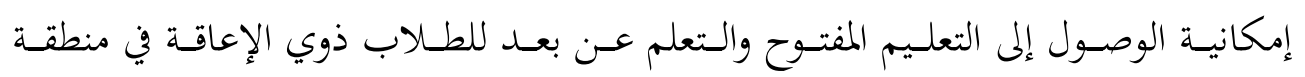


ماشونالاند الشـرقية التابعة لجامعة زمبابوي المفتوحة. تم استخدام المقابلات المنظمـة لطلب البيانـات مـن المستطلعين، تكونتت عينة الدراسـة مـن ستة مـن الطلاب المعـاقين في جامعـة زمبـابوي المفتوحـة، واثتي عشـر موظفـا أكاديميـا في منطقـة ماشـونالاند الشـرقية في زمبـابوي المفتوحـة. أشـارت نتائج الدراسـة إلى عـدم وجـود سياسة واضحة للتسجيل للطلبـة المعاقين، كمـا أشـارت نتـائج الدراسـة إلى عـدم وجـود سياسـة واضـحة بشـأن تقـــيم المسـاعدة الماليـة للطلاب ذوي الإعاقة. بالإضافة إلى عدم البنية التحتية للطلاب ذوي الإعاقة الجسدية حيث لا توجد سلالمج؛ فالأجهزة المساعدة ليست متاحة بسهولة للأشخاص ذوي الإعاقة. أما دراسة (2015) , Richardson فقد استهدفت المقارنة بين نتائج الطلاب الصـم وضعاف السـمع والطـلاب ذوي الإعاقـات الأخــى (كالإعاقـة البصـرية، والأوتيـزم، والإعاقة العقلية) الذين يتلقون دروسا عن طريق التعلم عن بعد بالجامعة المفتوحة بالمملكة المتحدة في عام 2012. أفادت نتائج الدراسة أن الطلاب الصمى وضعاف السمع قد أتمو دوراتهم التعليميـة وحصـلو على درجـات جيـدة مقارنـة بـالطلاب ذوي الإعاقـات الأخـرى، وخلصت الدراسة إلى أن فقدان السمع نفسه ليس له تأثير على التحصيل الدراسي، ولكن الإعاقات الإضافية قد يكون لما تأثير على الأداء التحصيلي للطالب. في حين استهدفت دراسة Erickson \& Larwin, (2016) التعرف على ما إذا كانت الدورات التدريبية عبر الإنترنت والتعليم عن بعد توفر الجسر اللازم للوصول إلى درجة ما بعد الثانوية للطلاب ذوي الإعاقة. قام الباحثان بتحليل عدد من الدراسات التي أجريت في هذا المحال وتوصل من خلال نتائج تلك الدراسات إلى أن أداء الطلبة ذوي الإعاقة أفضل بكثير في فصول التعلم عبر الإنترنت / التعلم مقارنة بأدائهم في فصول التعليم التقليدية .

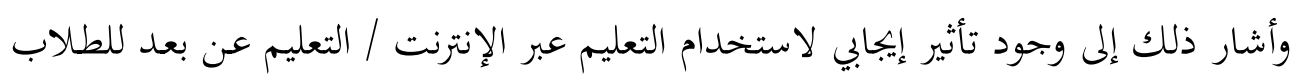
ذوي الإعاقة.

أمـا دراسة (2017) Baladoh et al., استهدفت هـدفت التعرف على تأثير المختبر الافتراضي على الإبحاز في الدوائر الإلكترونية لدى عينة من الطلاب ضعاف السمع. اتبعت الدراسة المنهج شبه التجريبي لقياس فاعلية المتغير المستقل (المختبر الافتراضي) لتطوير

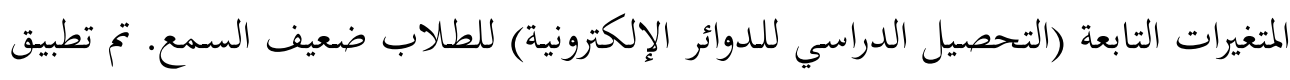


الدراسة على جميع طلاب قسم الالكترونيات والحوسبة في المرحلة الإعدادية المهنية في مدرسة الأمل لسماع السمع في المنصورة - مصر خـالال الفصل الدراسي الأول مـن العام الدراسي (2013-2014). اسـتخدمت الدراسـة بحموعـة تجريبيـة واحسـدة لـديها تم تطبيـق أدوات القياس المتمثلة في (اختبار التحصيل واختبار المهارات العملية) قبلي وبعد التطبيق. إذا واجه الطالب أي مشـكلة أثنـاء استـخدام المختبر الافتراضي، يمكـن أن يتواصـل مـع أصـدقائه أو المعلم من خلال وسائل الإعلام المتزامنة مثل غرف الدردشة أو غير متزامن مثل رسائل البريد

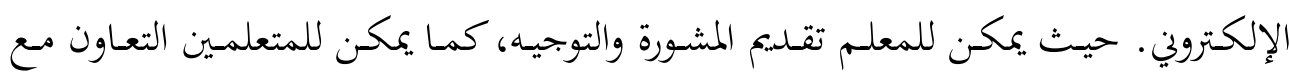

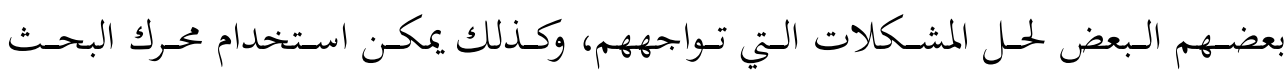
للحصول على أي معلومات في النظام أو على شبكة الإنترنت. أشارت نتائج الدراسة إلى وجسود فروق ذات دلالة إحصائية بـين القياسين القبلي والبعدي للدى عينة الدراسة لصـالح القياس البعدي.

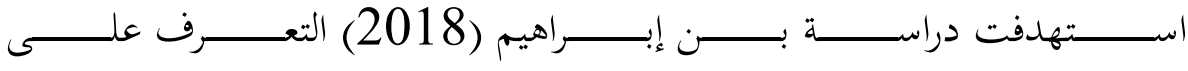

دور التعليم عن بعد في توسيع فرص دخول الطلبة الصم للتعليم العالي: البرامج المتاحة وجودة

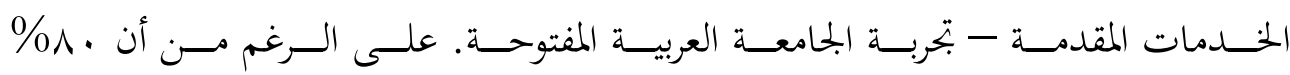
مـن الصـم في العـالم يتواجـدون في الـدول الناميـة، وفقـا للاتحـاد الـدولي للصـم ( World Federation Of the Deaf, 2015 )، إلا أن الواقع العربي أشار إلى وجود نقص في توسيع فرص دخولهم في مؤسسات التعليم العالي. ولذا استهدفت الدراسة الحالية وصف تحربـة الجحامعة العربيـة المفتوحسة، كمؤسسـة تعليم عـن بعـد، في تعليم الطلبـة الصـم، وتحديـد

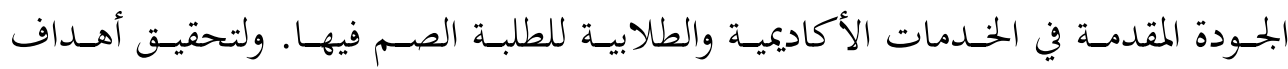
الدراسـة، تم وصف دور الجامعة العربية المفتوحـة في تعليم الصـم، مـن خهلال تحليـل الوثائق

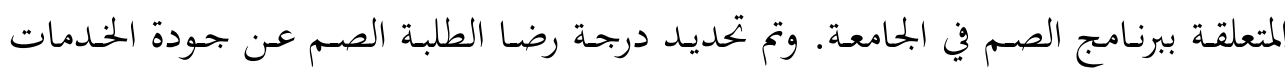
الأكاديمية والمساندة المقدمة لهم في الجامعة، من خحلال أداة استقصاء تم تصميمها وتطبيقها على VT طالبا وطالبة (Tr إناث، ع ع ذكور). توصلت الدراسة إلى وصف التعليم المقدم للطلبة الصم في الجامعة العربية المفتوحة ونشأته وعدد المستفيدين منه (الب ا طالبًا) والتطوير

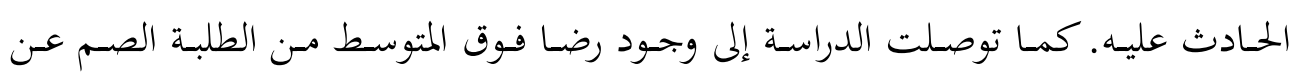


الخدمات المقدمة لهم في الجامعة، إلا أن درجة رضا الطلبة الذكور كانت أكبر من الإناث،

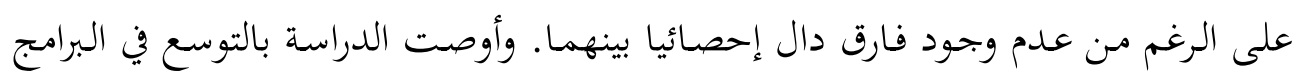

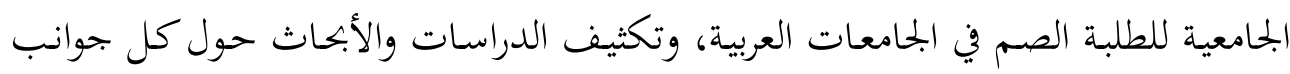

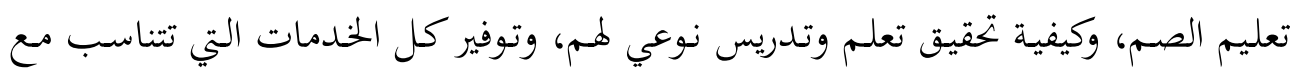
مواصفاةم واحتياجاهم الخاصة.

\section{تعليق على الدراسات والبحوث السابقة}

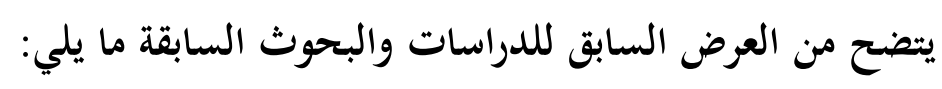
الاهتمام بتوفير فرص التعليم للأفراد ذوي الإعاقة السمعية.

(2) أصبح التعلم عن بعد مدخلاً بديلاً للتعلم المنتظم للأفراد ذوي الإعاقة السمعية. (3) يسهم التعلم عن بعد في تسليح ذوي الإعاقة السمعية بالمعرفة.

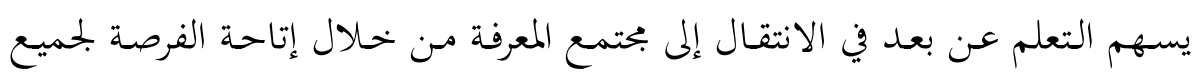

$$
\text { أفراده في امتلاكك المعرفة. }
$$

\section{منهجية البحث}

منهج البحث: استخدمت الباحثة المنهج الوصفي باعتباره أقرب المناهج العلمية

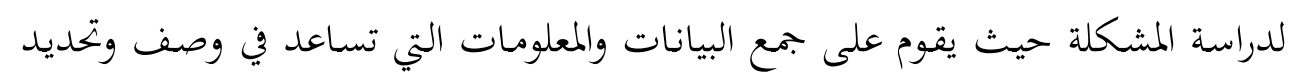
مشكلة البحث.

$$
\text { إجراءات البحث: }
$$

تمت إجراءات البحث على النحو التالي: تناولت الباحثة التعلم عن بعد وبحتمع المعرفة.

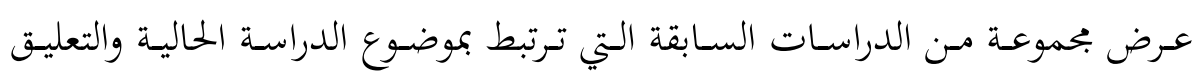

عليه.

وضع تصور مقترح لتفعيل التعلم عن بعد لدى المعاقين سمعيًا في التعليم الجامعي في 
يلعب التعليم الجامعي لدى ذوي الإعاقة السمعية دورًا رئيسًا في تطوير التعليم في كل

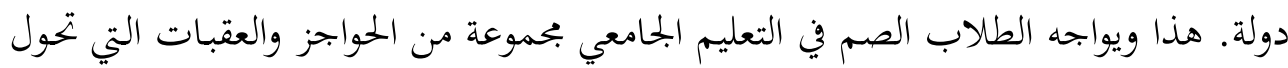

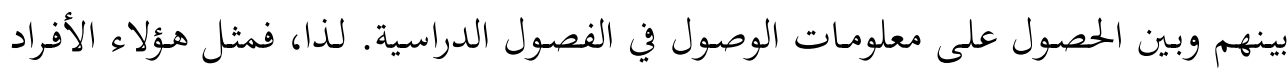

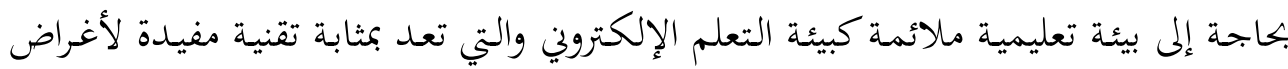

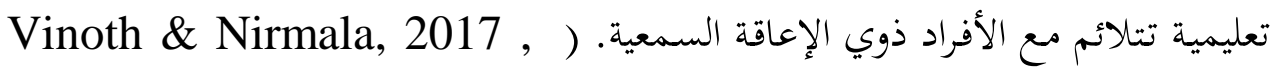

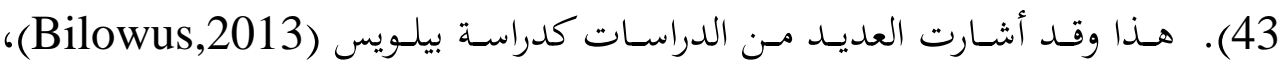
ودراسة (Martins et al., 2015) ودراسة (Debevc et al., 2010) إلى أهمية التعلم عن بعد لدى الأفراد ذوي الإعاقة السمعية. ومن خحلال التصور الحالي تحاول الباحثة

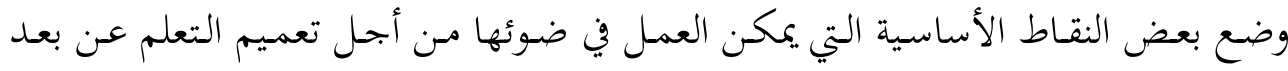

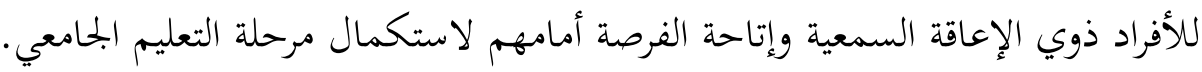

\section{فلسفة التصور المقترح:}

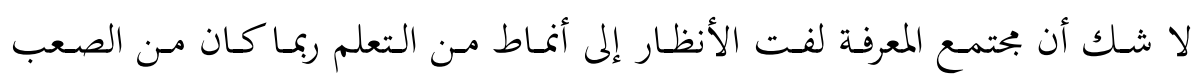

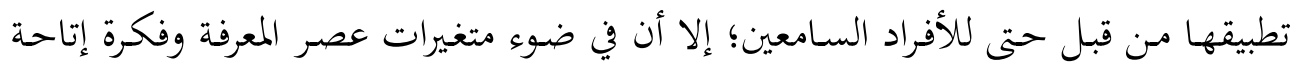

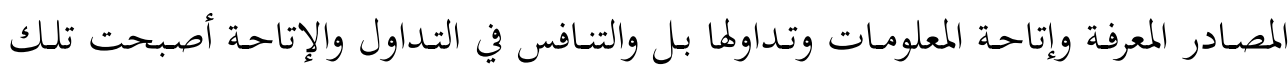

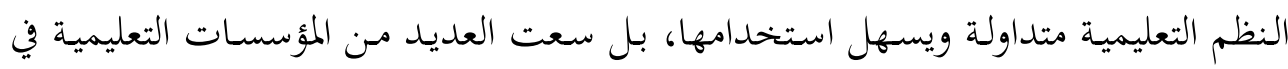

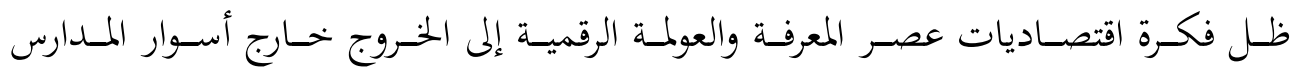

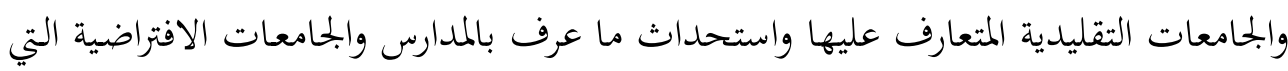
سهلت من عملية التعليم والتعلم لكل من المعلم والمتعلم. ومن ثم تكمن فلسفة التصور المقترح خلال هذه الدراسة في الأتي:

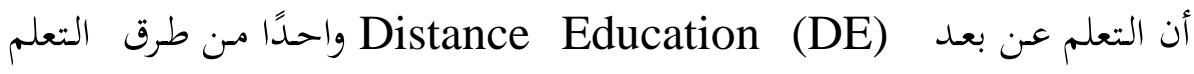
الحديثة مهِدِ لظهورها من خحلال تداول بعض أنماط للتعليم عن بعد مثل التعلم

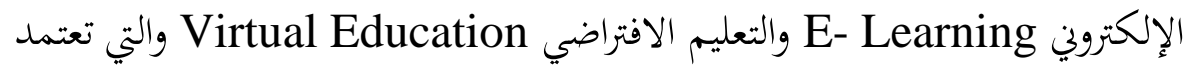
على تقنيات الحاسب وشبكة الإنترنت والوسائط المتعددة لنقل المادة التعليمية. 
يتغلب التعلم عن بعد على عاملي المسافة والزمن ومن ثم فهو وسيلة فعالة وخاصة

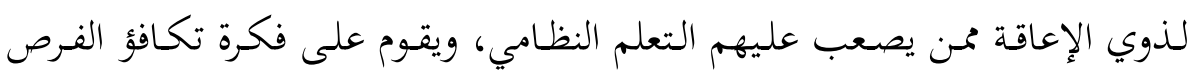
حتى بين فئات ذوي الاحتياجات الخاص ويفجر الطاقات الكامنة بداخلهم. يتصـف بحتمـع المعرفـة بسـرعة الاسـتجابة للتغيسير أي أن مؤسســات بحتمـع المعرفـة الحلكوميـة والخاصـة ومنظمـات المحتمـع المـدي تبعـد عـن أدوارهـا التقليديـة مـن خـلال ممارسة السرعة و الدقة الفائقة في العمل و التعرف على الأمور التي قدد المحتمع، هذا

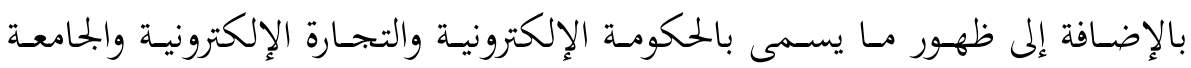
الافتراضـية والـتي مـن شـأفم أن يسهموا في إحـداث تغيسير على طبيعـة التعـاملات

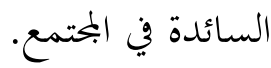

يتميز التعلم عن بعد طريقة فعالة في تداول المعرفة والمحاكة للواقع، فمن خلاله يمكن (4) إجراء التجارب في المعامل الافتراضية التي ربما لو تمت في الواقع تتكلف تكلفة باهظة من طار وبها العديد من المخاطر والتهديدات على الفئات ذوي الاحتياجات الخاصة. بحتمع المعرفة يتميز بسرعة الإدارة التي تعتمد على سرعة الاستجابة للتغيير، وسرعة اكتساب القدرات والمعارف الجديدة، وسرعة الابتكار والتجديد والتطور. يتسم التعلم في بحتمع المعرفة بالتحول نحو التعلم للعمل وذلك بتوظيف المعرفة الملائمة

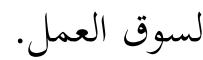
يسعى بحتمع المعرفة نحو التحول من استهلاك المعرفة إلى إنتاجها حيث أصبح بناح النظم التعليمية يقاس بمدى قدرتا على إعداد كوادر بشرية مؤهلة تشارك في زيادة معدلات الإنتاج و الاستثمار، و تسهم بإيجابية في بناء صرح التحضر العلمي.

\section{المبادئ والأسس التي يقوم عليها التصور المقترح:}

ينبغي مراعاة هذه المبادئ عند وضع التصور المقترح وهى: وضع أهداف للتصور المقترح تتسم بالتحديد والقدرة على التحقيق.

مناسـبة التصـور المقـترح لطبيعـة البيئـة التعليميـة الـتى ينفــذ فيهـا وخصـائص العينـة 
(3) ق قابلية التصور المقترح للتطبيق في حدود الإمكانات المادية والبشرية المتاحة.

(4) مراعاة المخاطر والتهديدات التي قد تحول دون تطبيق هذا التصور.

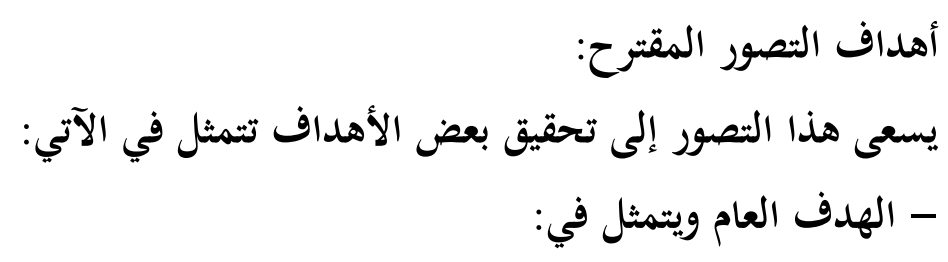

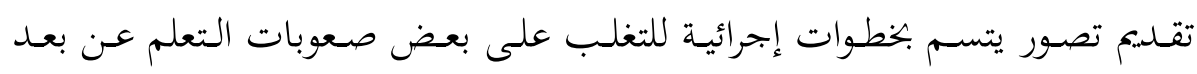

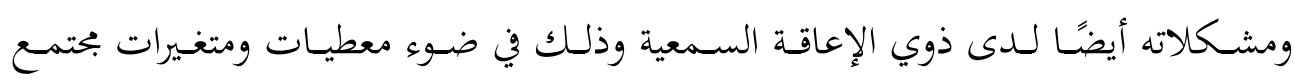

المعرفة.

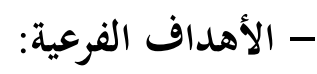

(1) الوقوف على واقع التعلم عن بعد ببيئة تعليم ذوي الإعاقة بصفة عامة.

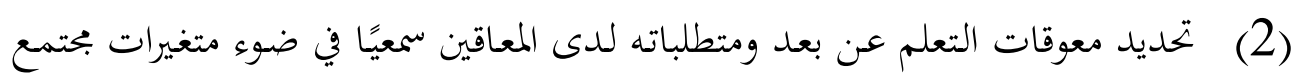

المعرفة وتحدياته.

(3) محاولة التعرف على فلسفة التعلم عن بعد وتطويعه لفئة المعاقين سمعيًا.

(4) ت تبنى فلسفة التطوير والتحسين لمواجهة التحديات التى تواجه الإدارة المدرسية.

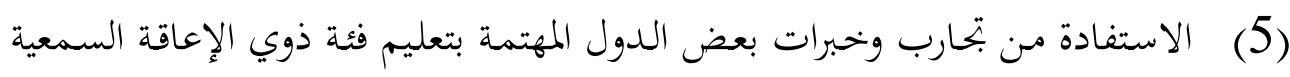

وخاصة في ضوء متغيرات بحتمع المعرفة.

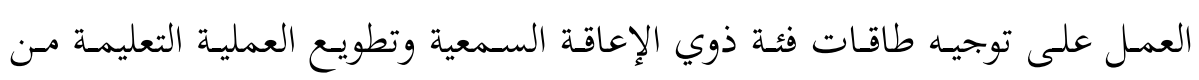

خلال الواقع الافتراضي لهم.

تنمية القدرة على الابتكار والإبـاع لـدى فئة ذوي الإعاقة السمعية حتى يمكنهم

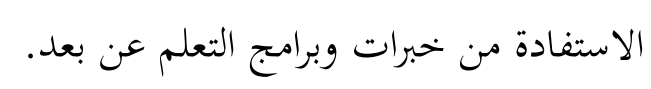

الركائز الأساسية للتصور المقترح:

أعتمد التصور المقترح التالي على بعض المرتكزات الأساسية التي بني في ضوئها هذا

التصور، وتمثلت تلك المرتكزات في الآتي: 
(1) ما تم التوصل إليه من معلومات ونتائج دراسات سابقة خلال الإطار النظري والبحثي

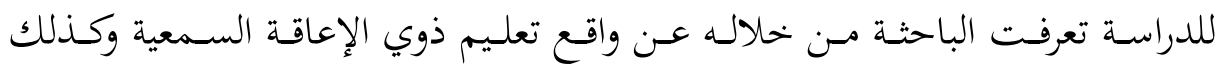

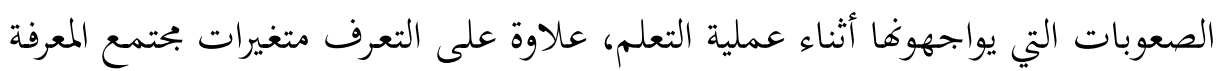
التي تسهم في تحسين والتغلب على مشكلات التعلم عن بعد وخاصة لدى فئة المعاقين

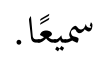

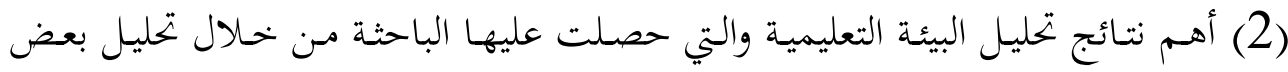

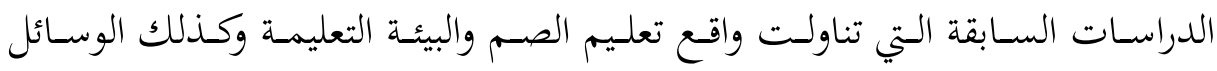

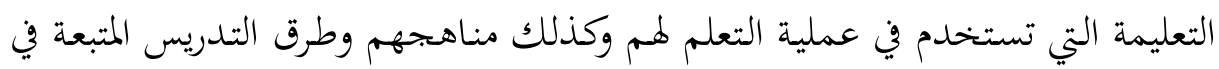
تعلمهم. (3) إجـراء بعض المقـابلات الشخصية ببعض المؤسسـات التعليميـة المنوطـة بتعليم الصــم

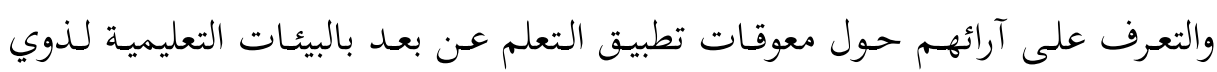

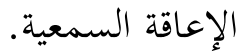

\section{مراحل تطبيق التصور المقترح:}

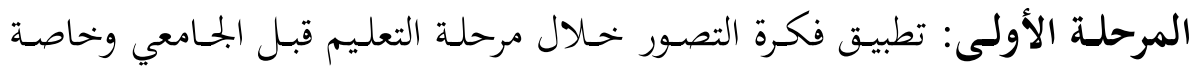

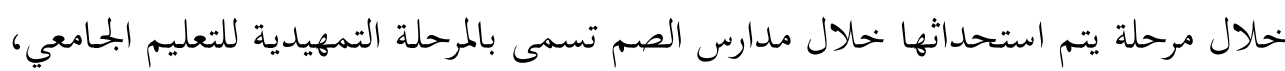

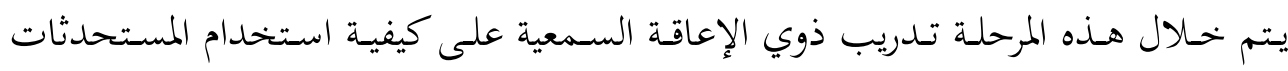
والتقنيات التكنولوجية في بيئات التعلم وخاصة ما عرف بالمعامل الافتراضية وكيف يتم إجراء

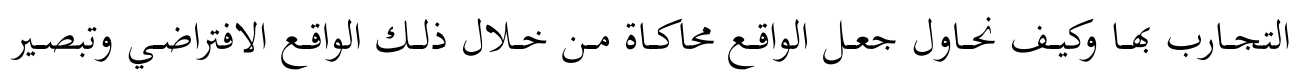

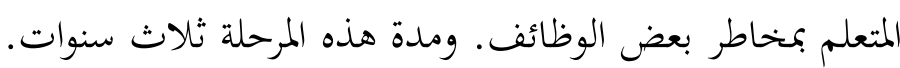

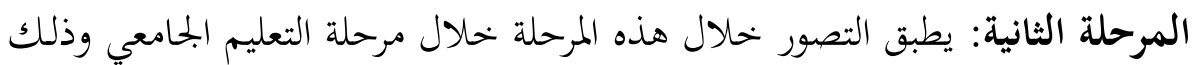

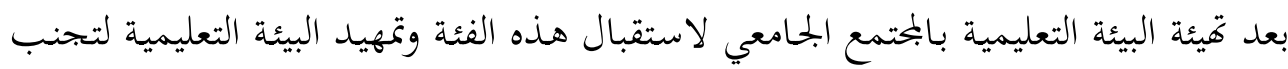

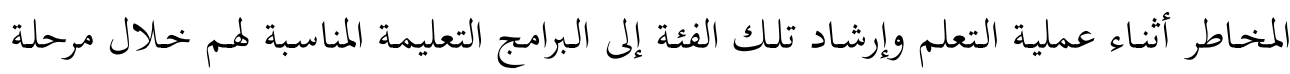
التعليم الجامعي. ومدة هذه المرحلة أربع سنوات. 
متطلبات تطبيق التصور المقترح

نشر ثقافة التعلم عن بعد بالبيئات التعليمية لذوي الإعاقة السمعية.

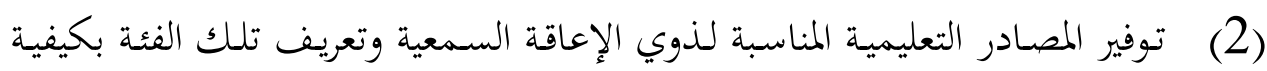

$$
\text { الحصول ومتطلبات الحصول عليها. }
$$

تدريب كوادر تعليمية وتدريسية بالمرحلة الجحامعية على كيفية التدريس عن بعد لذوي

$$
\text { الإعاقة السمعية. }
$$

كتيئة بيئة تعليمية مناسبة تسمح بالتفاعل بين المتعلم والأستاذ وخاصة من فئة ذوي

$$
\text { الإعاقة السمعية. }
$$

توفير قاموس إشاري موحد يسهل عملية التواصل والتفاعل بين الطالب والأستاذ.

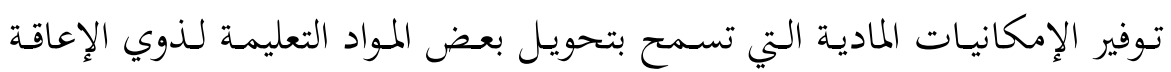

$$
\text { السمعية بلغة الإشارة. }
$$

الجهات المنوط بها تنفيذ التصور: التصارة

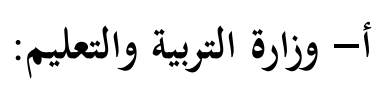

ويتمثل دور وزارة التربية والتعليم في تنفيذ هذا التصور من خلال الأتي:

$$
\begin{aligned}
& \text { 1) تفعيل دور وزارة التربية والتعليم في إعداد دورات تدريبية. } \\
& \text { 2) عقد ورش عمل حول لغة الإشارة وكيفية إتقاها. } \\
& \text { 3) إنشاء وحدة للتعلم عن بعد بمدارس الأمل للصم. }
\end{aligned}
$$

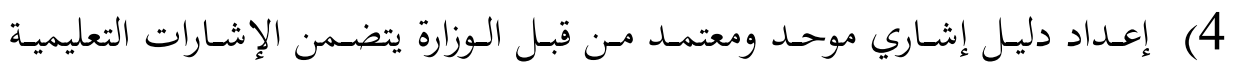

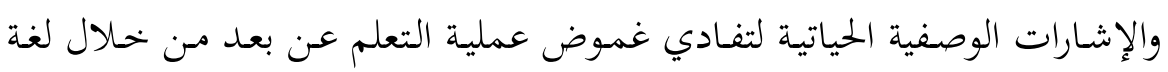

$$
\text { الإشارة. }
$$

5) توفير الكوادر البشرية من المعلمين المدربين على لغة الإشارة بل المتقنين للغة الإشارة

$$
\text { ب- وكيفية استخدامها في عملية التعليم والتعلم. }
$$

يتمثل دور وزارة التعليم العالي في تنفيذ هذا التصور من خحلال الأتي 
1) إتاحة الفرصة لذوي الإعاقة السمعية بشكل أوسع للالتحاق ببرامج التعليم

الجامعي.

2) توفير كوادر جامعية مدربة على التواصل والتدريس لذوي الإعاقة السمعية.

3) تتهيد البيئة التعليمية افتراضية خحلال وحدة التعلم عن بعد لإتاحة المواد التعليمة

$$
\text { التي تصلح لطبيعة ذوي الإعاقة السمعية. }
$$

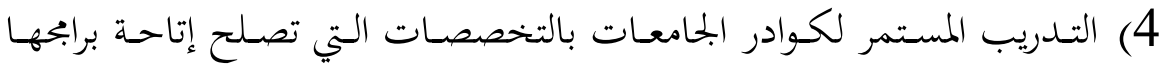

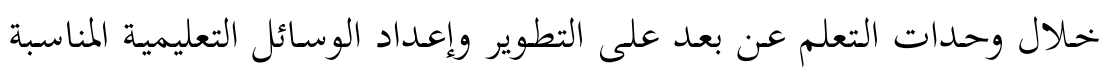

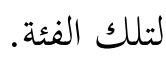

5) توفير الإمكانيات المادية والكوادر البشرية المؤمنة بأحقية ذوي الإعاقة السمعية

$$
\text { في التعلم خلال برامج التعليم العالي. }
$$

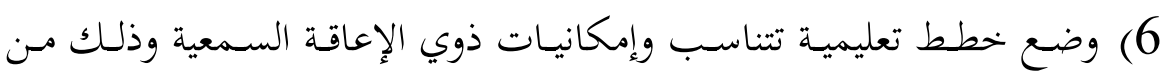
خلال إجراء اختبار قبول بالجامعات لتلك الفئة.

\section{مؤشرات المتابعة والتقويم للتصور المقترح:}

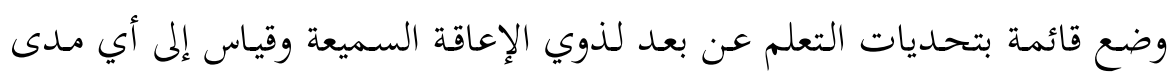
تم التحقق من زوال تلك التحديات. تدريب الطلاب والقائمين بالتدريس لذوي الإعاقة السمعية على إتقان لغة الإشارة

$$
\text { من خلال قاموس أشاري موحد. }
$$

هل تم إعداد الخطط التنفيذية للتصور.

هل تم تحديد أدوار الجهات المنوط بها تطبيق التصور.

متابعة مصادر التمويل لمراكز التعلم عن بعد بالمدارس والجامعات. 


\section{المراجع}

آل رفعه، مسفر بن جبران معيض (2014). بتحيد دور المعلم السعودي للتوائم مع بحتمع

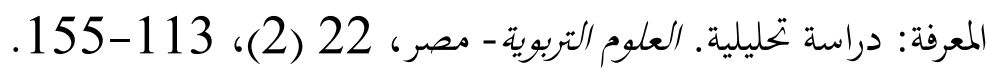

توفيق، صلاح الدين محمد و موسى، هاني محمد يونس ( 2007). دور التعلم الإلكتروني في بناء بجتمع المعرفة العربي:دراسة إستشرافية. بجلة البحوث النفسية والتربوية مانية - كلية التربية

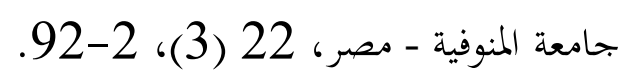

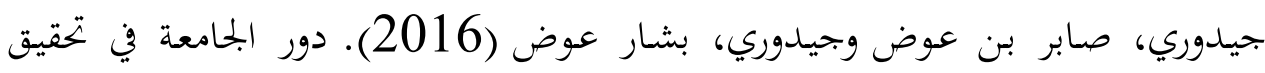

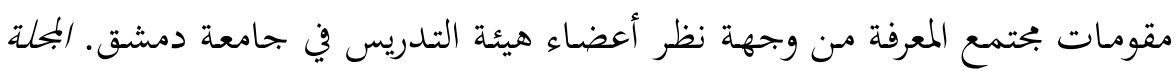

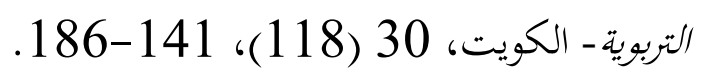

حسن، حسن النور (2013). دور المكتبات الوطنية في بناء بحتمع المعرفة: دراسة حالة

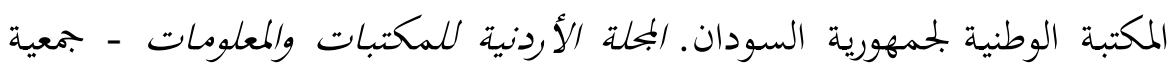

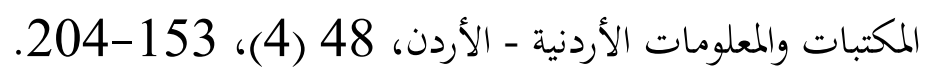

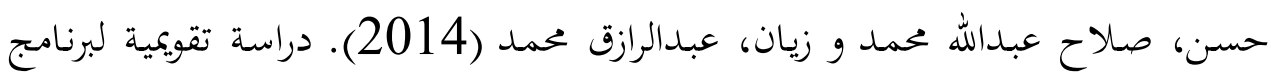
التعلم الإلكتروني كصيغة للتعليم عن بعد في جامعة الإمام محمد بن سعود الإسلامية في ضوء معايير الجودة الشاملة. دراسات تربويه ونغسية: بحلة كلية التربية بالزقازيق -

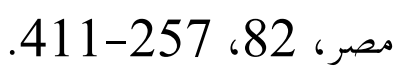

رضوان، وائل توفيق و عيسى، عمرو محمد حامدا لحد (2016). تطوير صناعة القرار بالمؤسسات التعليمية في ضوء تحولات بحتمع المعرفة. الثقافة والتنمية - مصر، 16

$$
\text { .382-327، (101) }
$$

زايد، أمير عبدالسلام (2012). التعليم المفتوح و إنماء بحتمع المعرفة: الفلسفة - التحديات

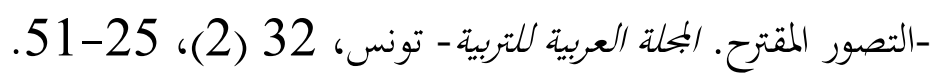




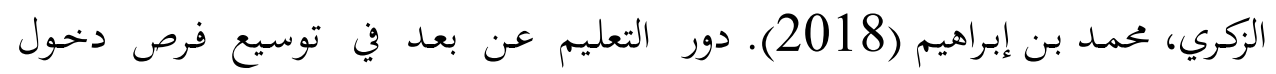

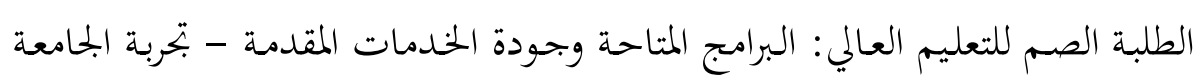

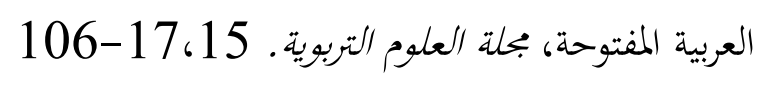
سويلم، جملاء تركي. (2014). الاحتياجات التدريبية لمديرات المدارس في بحتمع المعرفة.

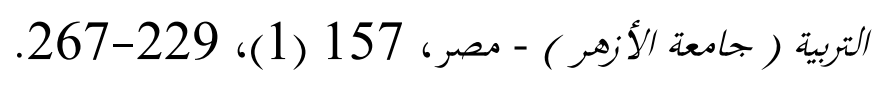

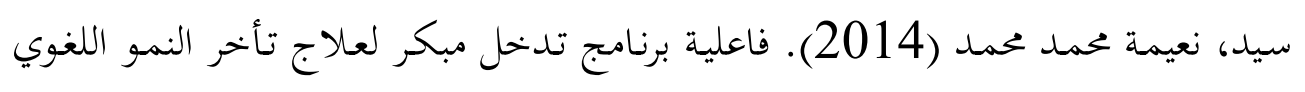

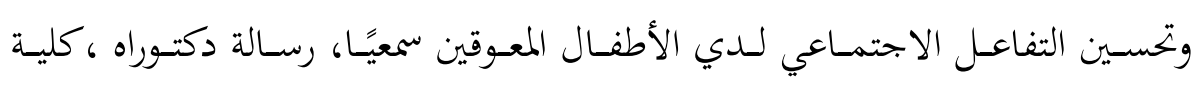
التربية:جامعة عين شمس.

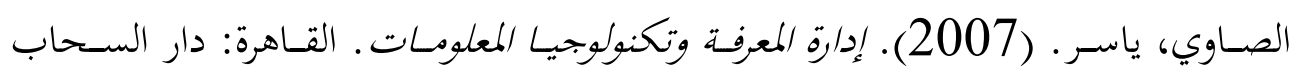
للنشر والتوزيع. عبدالتواب، عبدالتواب عبداللاه وشاكر، كريمة محمود، عبدالمعطي، أحمد حسين. (2015).

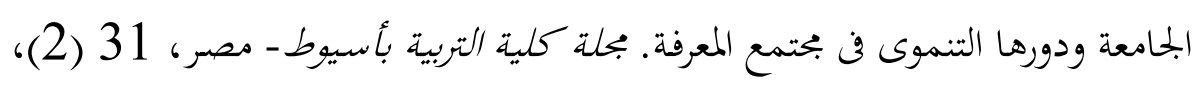

$$
\text { 450-394 }
$$

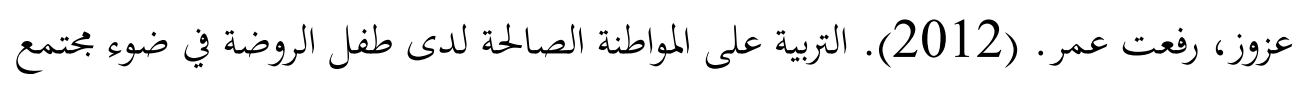

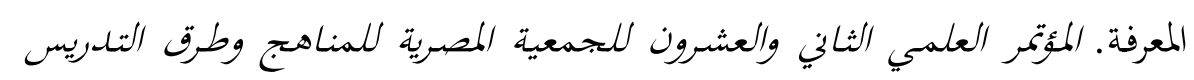

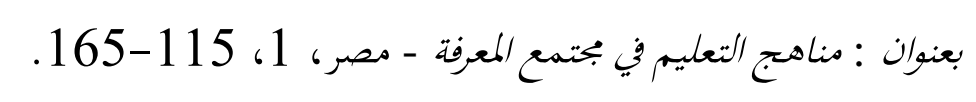

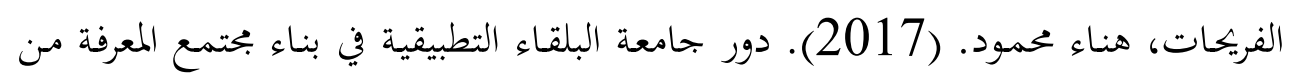

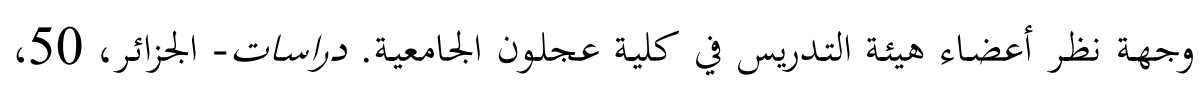

$$
\text { .99-79 }
$$

القحطاني، جوزاء بنت محمد. (2015). دور مكتبة الملك فهد الوطنية في بناء بحتمع

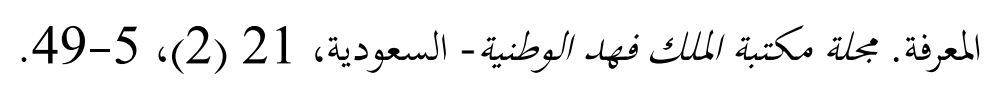

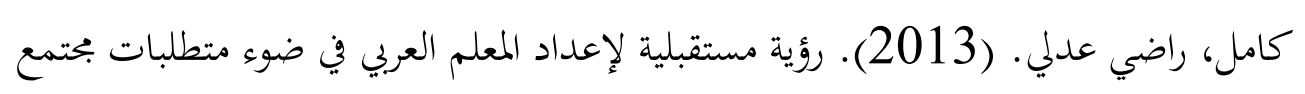

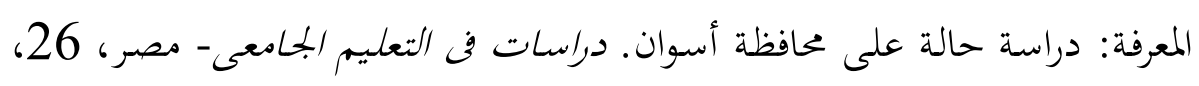


النصار، انتصار بنت عبدالله بن أحمد. (2016). دور التعليم الثانوي في تحقيق متطلبات

بحتمع المعرفة من وجهة نظر معلمات المرحلة الثانوية في مدينة بريدة. رسالة ماجستير

غير منشورة، كلية التربية، جامعة القصيم.

Ahmad,I \& Bokhari,M (2013 ). The Combine Effect of Synchronous and Asynchronous E-Learning on Distance Education. International Journal of Computer Science Issues, 10 (1), 546-550

Baladoh,S., Elgamal,A \& Abas,H. (2017). Virtual lab to develop achievement in electronic circuits for hearing-impaired students. Educ Inf Technol, 22,2071-2085.

Bhuiyan,S. (2011). Transition Towards a Knowledge-Based Society in Post-Communist Kazakhstan: Does Good Governance Matter?. Journal of Asian and African Studies, 46(4) 404-421.

Bilowus,M. (2013). How online learning can benefit deaf and hard of hearing people. Master, Rochester Institute of Technology.

Boboye,J. (2016). Improving Engagement For Distance Learning Students Through Non-Face-To-Face Counseling: An Action Research Study. Ph.D, Capella University.

Bušelić,M. (2012). Distance Learning - concepts and contributions. Oeconomica Jadertina,23-34.

Charles,M. (2015). Assessing The Challenges Of Teaching And Learning Of Hearing Impaired Students Enrolled In Regular Primary And Secondary Schools In Tanzania. Master, Open University Of Tanzania.

Coogle,C \& Floyd,K. (2015). Synchronous and Asynchronous Learning Environments of Rural Graduate Early Childhood Special Educators Utilizing Wimba and Ecampus. Journal of Online Learning and Teaching, 11 (2), 173-187.

Cooper, M.(2014). Meeting the needs of disabled students in online distance education - an institutional case study from The Open University, UK. Distance Education in China, 12 , 18-27.

Debevc,M., Kosec,P.\& Holzinger,A. (2010). E-Learning Accessibility for the Deaf and Hard of Hearing - Practical 
Examples and Experiences. Springer-Verlag Berlin Heidelberg, 203-213.

Debevc,M., Stjepanovi_c,Z \& Holzingerc,A. (2012). Development and evaluation of an e-learning course for deaf and hard of hearing based on the advanced Adapted Pedagogical Index method. Interactive Learning Environments, 1-16.

Dodo,O. (2013). An Analysis of Challenges Faced by Students Learning in Virtual and Open Distance Learning System: A Case of Bindura University of Science Education (BUSE). Journal of Global Peace and Conflict, 1(1), 28-40.

Erickson,M \& Larwin,K. (2016). The Potential Impact of Online/Distance Education for Students with Disabilities in Higher Education. International Journal of Evaluation and Research in Education, 5(1), 76-81.

Gashi, F. (2015). Knowledge society in the context of the economic development with a focus in Kosovo. Academic Journal of Business, Administration, Law and Social Sciences, 1 (2), 308-313.

Kigotho,L. (2016). Barriers Faced By Students With Hearing Impairment In Inclusive Learning Environment, A Case Of The University Of Nairobi. Master, University Of Nairobi.

Kujath,H \& Stein,A. (2009). Spatial Patterns in the Knowledge Society.In Kilper,H (2009), New Disparities in Spatial Development in Europe, Springer.

Lei, S. \& Gupta, R.(2010). College distance education courses: Evaluating benefits and costs from institutional, faculty, and students' perspectives. Education, 130(4), 616-631.

Liakou,M., \& Manousou,E.(2015). Distance Education For

People With Visual Impairments. European Journal of Open, Distance and e-Learning , 18 (1), 72-84.

Mapuranga,B \& Nyenya,T. (2014). Open and Distance Learning Accessibility to Learners with Disabilities. International Journal of Humanities Social Sciences and Education , 1(4), $1-12$.

Martins,P., Rodrigues,H., Rocha,T., Francisco,M \& Morgado,L. (2015). Accessible options for Deaf people in e-Learning 
platforms: technology solutions for Sign Language translation. Procedia Computer Science, 67, 263-272.

Mpofu,J \& Chimhenga,S. (2013). Challenges faced by Hearing Impaired pupils in learning: A case study of King George VI Memorial School. IOSR Journal of Research \& Method in Education, 2 (1), 69-74.

Murphy,E., Rodríguez-Manzanares,M \& Barbour,M. (2011). Asynchronous and synchronous online teaching: Perspectives of Canadian high school distance education teachers. British Journal of Educational Technology, 42 (4) , 583-591.

Nadelman,C. (2013). Exploring Organizational and Cultural Barriers to Developing Distance Learning Programs in Higher Education. Ph.D, Northcentral University.

Ohene,J. (2014). Challenges Faced by Distance Education Students of the University of Education, Winneba: Implications for Strategic Planning. Journal of Education and Training, 1 (2), 156-176.

Oswal, S. K., \& Meloncon, L. (2014). Paying Attention to Accessibility When Designing Online Courses in Technical and Professional Communication. Journal of Business and Technical Communication, 28(3) 271-300.

Panchabakesan,S. (2011). Problems And Prospective In Distance Education In India In The 21st Century. 30, 113 122.

Pattnayak,J \& Pattnaik,S. (2016). Integration of Web Services with E-Learning for Knowledge Society. Procedia Computer Science, 92,155-160.

Pittman,C. (2013). The impact of student motivation on participation and academic performance in distance learning. Ph.D, Mississippi State University.

Purwaningrum,F. (2016). Managing challenges and cultivating collaborations in Indonesia's knowledge society. John Wiley \& Sons Ltd, 63-87.

Richardson,J \& Woodley,A. (2001). Approaches to studying and communication preferences among deaf students in distance education. Higher Education, 42 (1), 61-83. 
Richardson,J. (2015). Academic attainment in deaf and hard-ofhearing students in distance education. The Journal of Open, Distance and e-Learning, 30 (2), 164-177.

Savickaite,A. (2013). Critical Points in Distance Learning System. Socialines Technologijos Social Technologies, 3(1), 221-230.

Smyrnova-Trybulska,E. (2010). Use Of Distance Learning In The Training Of Professionals In The Knowledge Society. 137-161.

Topaloglu,A \& Topaloglu,M. (20009). Distance education applications in concept acquisition for disabled individuals/ special education for handicapped. Procedia Social and Behavioral Sciences, 1, 1008-1011.

Va“limaa,J \& Hoffman,D. (2008). Knowledge society discourse and higher education. High Educ, 56, 265-285.

Vinoth,N \& Nirmala,K. (2017). Deaf Students Higher Education System Using E-Learning. Journal of Education and Learning, 11 (1), 41-46. 